\title{
Microstructural Characterization of Ceramic Materials by Small Angle Neutron Scattering Techniques
}

\author{
K. Hardman-Rhyne, N. F. Berk, and E. R. Fuller, Jr. \\ National Bureau of Standards, Washington, DC 20234
}

\begin{abstract}
Accepted: December 1, 1983
The use of small angle neutron scattering (SANS) techniques for ceramic materials is discussed. Two areas are emphasized: 1) diffraction for microstructural phenomena of less than $100 \mathrm{~nm}$, and 2) beam broadening for microstructural phenomena greater than $90 \mathrm{~nm}$.
\end{abstract}

Key words: ceramic materials; green compact $\mathrm{YCrO}_{3}$; porosity; $\mathrm{Si}_{3} \mathrm{~N}_{4}$; small angle neutron scattering.

\section{Introduction}

Small angle neutron scattering (SANS) techniques are used to study microstructural phenomena in the range of 1 to $10^{4} \mathrm{~nm}$ in size. Since they cover a wide range of sizes, these techniques are particularly useful in studies of ceramic processing and distributed damage in ceramics. While many metal and alloy systems have used SANS techniques, few experiments have been published on ceramic materials. This is not surprising considering the difficulties inherent in analyzing SANS data on these materials. Often ceramics have several microstructural components such as residual voids from the sintering process, inclusions or impurities from starting materials, second phases, and microcracks or cavities from temperature and/or pressure treatments, as well as dislocations present in the material. All these effects produce small angle neutron scattering. It is important to either eliminate all effects except the one of interest or to identify the effects through complementary studies

\footnotetext{
About the Authors, Paper: K. Hardman-Rhyne, a chemist, and N. F. Berk and E. R. Fuller, Jr., physicists, are with the NBS Center for Materials Science. The work reported on here was supported in part by the Army Materials and Mechanics Research Center with funds provided by the Department of Energy under Interagency Agreement DOE/AMMRC (DOE-1A No. DEA101-77-CS5-1017).
}

that use other techniques such as electronic or optical microscopy. While these complementary techniques can identify defects, voids, and second phases, SANS can quantify these effects throughout the bulk of the materials in a nondestructive way due to the general nature of neutrons.

Neutrons are an excellent nondestructive probe of microstructure because the thermal neutron energies are very low and neutrons are not absorbed in most materials. Since the neutrons primarily interact with the nucleus of the atoms, the neutron beam is highly penetrating without disturbing the sample. This allows us to examine the bulk of the material whereas $x$-ray and other techniques are more sensitive to surface phenomena. One strength of neutron scattering is its dependence on the chemical elements present in the material through a quantity called the coherent scattering length, $b[1]^{1}$. Since $b$ values vary in an unsystematic way from one element to another, differences between elements with similar atomic numbers can be detected, e.g., aluminum and magnesium or iron and manganese (see table 1).

Magnetic and isotope behavior can be studied with SANS techniques. Neutrons have a magnetic moment which interacts with the electrons in the material. The magnetic and structural properties of many ferrites and rare earth garnets have been examined with neutron scattering. Isotope studies involving hydrogen

\footnotetext{
${ }^{1}$ Numbers in brackets indicate references at the end of this paper.
} 
Table 1. Bound values of coherent scattering length, incoherent scattering cross-section and absorption cross-section for elements and isotopes (from Ref. [1])

\begin{tabular}{|c|c|c|c|c|c|}
\hline $\begin{array}{l}\text { Atomic } \\
\text { number }\end{array}$ & $\begin{array}{l}\text { Element } \\
\text { or } \\
\text { isotope }\end{array}$ & $\begin{array}{l}\text { Nucl. } \\
\text { spin }\end{array}$ & $\begin{array}{l}\text { Scattering length } \\
\quad b\left(10^{-12} \mathrm{~cm}\right)\end{array}$ & $\begin{array}{c}\text { Incoherent } \\
\text { scattering cross-section } \\
\sigma_{\text {inc }}(\text { barn })\end{array}$ & $\begin{array}{c}\text { Absorption } \\
\text { cross section for } \lambda=1.8 \AA \\
\sigma_{\text {abs }}(\text { barn })\end{array}$ \\
\hline \multirow[t]{3}{*}{1} & ${ }^{1} \mathbf{H}$ & $1 / 2$ & $-0.3740(1)$ & 79.7 & 0.33 \\
\hline & ${ }^{2} \mathrm{H}=\mathrm{D}$ & 1 & $0.6674(6)$ & 2.0 & 0.00046 \\
\hline & ${ }^{3} \mathrm{H}=\mathrm{T}$ & $1 / 2$ & $0.50(3)$ & & \\
\hline \multirow[t]{2}{*}{2} & ${ }^{3} \mathrm{He}$ & $1 / 2$ & 0.62 & 1.2 & 5500 \\
\hline & ${ }^{4} \mathrm{He}$ & 0 & $0.30(2)$ & 0 & $<0.007$ \\
\hline \multirow[t]{3}{*}{3} & $\mathrm{Li}$ & & $-0.203(5)$ & 0.7 & 71 \\
\hline & ${ }^{6} \mathrm{Li}$ & 1 & $0.18+0.025 i$ & & 945 \\
\hline & ${ }^{7} \mathrm{Li}$ & $3 / 2$ & -0.233 & 0.7 & \\
\hline 4 & $\mathrm{Be}$ & $3 / 2$ & $0.78(4)$ & $0.005(1)$ & 0.010 \\
\hline \multirow[t]{3}{*}{5} & B & & $0.535(6)+0.021 i$ & $0.7(2)$ & 755 \\
\hline & ${ }^{10} \mathrm{~B}$ & 3 & $0.14+0.11 i$ & & 3813 \\
\hline & ${ }^{11} \mathrm{~B}$ & $3 / 2$ & 0.60 & & \\
\hline \multirow[t]{3}{*}{6} & $\mathrm{C}$. & & $0.66484(13)$ & $<0.018$ & 0.0033 \\
\hline & ${ }^{12} \mathrm{C}^{4}$ & 0 & 0.665 & 0 & \\
\hline & ${ }^{13} \mathrm{C}$ & $1 / 2$ & 0.60 & 1.0 & \\
\hline \multirow[t]{3}{*}{7} & $\mathbf{N}$ & & $0.936(2)$ & $0.46(12)$ & 1.88 \\
\hline & ${ }^{14} \mathrm{~N}$ & 1 & 0.94 & & \\
\hline & ${ }^{15} \mathrm{~N}$ & $1 / 2$ & 0.65 & & \\
\hline \multirow[t]{4}{*}{8} & 0 & & $0.5803(5)$ & $<0.015$ & $<0.0002$ \\
\hline & ${ }^{16} 0$ & 0 & 0.580 & 0 & \\
\hline & ${ }^{17} 0$ & $5 / 2$ & 0.578 & & \\
\hline & ${ }^{18} 0$ & 0 & 0.600 & 0 & \\
\hline 9 & F & $1 / 2$ & $0.566(2)$ & 0.0004 & $<0.01$ \\
\hline 10 & $\mathrm{Ne}$ & & 0.46 & $<0.11$ & $<2.8$ \\
\hline 11 & $\mathrm{Na}$ & $3 / 2$ & $0.363(2)$ & $1.75(3)$ & 0.505 \\
\hline \multirow[t]{4}{*}{12} & $\mathrm{Mg}$ & & $0.5375(4)^{b}$ & $0.04(3)$ & 0.063 \\
\hline & ${ }^{24} \mathrm{Mg}$ & 0 & 0.55 & 0 & \\
\hline & ${ }^{25} \mathrm{Mg}$ & $5 / 2$ & 0.36 & & \\
\hline & ${ }^{26} \mathrm{Mg}$ & 0 & 0.49 & 0 & \\
\hline 13 & $\mathrm{Al}$ & $5 / 2$ & $0.3446(5)$ & $<0.01$ & 0.230 \\
\hline 14 & $\mathrm{Si}$ & & $0.41491(10)$ & $<0.017$ & 0.16 \\
\hline 15 & $\mathbf{P}$ & $1 / 2$ & $0.513(1)$ & $<0.23$ & 0.2 \\
\hline 16 & S & & $0.2847(1)$ & $0.012(4)$ & 0.52 \\
\hline \multirow[t]{3}{*}{17} & $\mathrm{Cl}$ & & $0.95792(8)$ & $5.9(3)$ & 33.6 \\
\hline & ${ }^{35} \mathrm{Cl}$ & $3 / 2$ & 1.18 & & \\
\hline & ${ }^{37} \mathrm{Cl}$ & $3 / 2$ & 0.26 & & \\
\hline \multirow[t]{2}{*}{18} & A & & $0.18(2)$ & $0.27(12)$ & 0.66 \\
\hline & ${ }^{36} \mathrm{~A}$ & 0 & 2.43 & 0 & \\
\hline \multirow[t]{2}{*}{19} & $\mathbf{K}$ & & $0.371(2)$ & $0.38(11)$ & 2.07 \\
\hline & ${ }^{39} \mathrm{~K}$ & $3 / 2$ & 0.37 & & \\
\hline \multirow[t]{3}{*}{20} & $\mathrm{Ca}$ & & $0.490(3)$ & $<0.06$ & 0.46 \\
\hline & ${ }^{40} \mathrm{Ca}$ & 0 & 0.49 & 0 & \\
\hline & ${ }^{44} \mathrm{Ca}$ & 0 & 0.18 & 0 & \\
\hline 21 & Sc & $7 / 2$ & $1.215(13)$ & $0.446(23)$ & 24 \\
\hline
\end{tabular}

and deuterium are also possible because the neutron scattering behavior of these elements is very different. This capability is often used in biological or polymer research.

This paper will discuss several NBS experiments on ceramic materials with a greater emphasis on SANS techniques rather than the actual pertinent values obtained. The main intention here is to emphasize the advantages and limitations of these techniques and to spark interest in further SANS ceramic research studies. We will divide the measurement discussion into three parts, as follows: 1) the diffraction limit which includes small particles or defects in the range of 1 to $100 \mathrm{~nm}, 2$ ) the multiple refraction limit which includes large particles and defects, usually $20 \mu \mathrm{m}$ or greater, and 3 ) the beam broadening region which lies between these two limits. However, preceding this discussion are two sections, one on the SANS 
Table 1 (Continued)

\begin{tabular}{|c|c|c|c|c|c|}
\hline $\begin{array}{l}\text { Atomic } \\
\text { number }\end{array}$ & $\begin{array}{l}\text { Element } \\
\text { or } \\
\text { isotope }\end{array}$ & $\begin{array}{l}\text { Nucl. } \\
\text { spin }\end{array}$ & $\begin{array}{l}\text { Scattering length }{ }^{\mathrm{a}} \\
\quad b\left(10^{-12} \mathrm{~cm}\right)\end{array}$ & $\begin{array}{c}\text { Incoherent } \\
\text { scattering cross-section } \\
\sigma_{\text {inc }}(\text { barn })\end{array}$ & $\begin{array}{c}\text { Absorption } \\
\text { cross section for } \lambda=1.8 \AA \\
\sigma_{\text {abs }}(\text { barn })\end{array}$ \\
\hline \multirow[t]{6}{*}{22} & $\mathrm{Ti}$ & & $-0.337(2)$ & $2.71(22)$ & 5.8 \\
\hline & ${ }^{46} \mathrm{Ti}$ & 0 & 0.48 & 0 & \\
\hline & ${ }^{47} \mathrm{Ti}$ & $5 / 2$ & 0.33 & & \\
\hline & ${ }^{48} \mathrm{Ti}$ & 0 & -0.58 & 0 & \\
\hline & ${ }^{49} \mathrm{Ti}$ & $7 / 2$ & 0.08 & & \\
\hline & ${ }^{50} \mathrm{Ti}$ & 0 & 0.55 & 0 & \\
\hline \multirow[t]{2}{*}{23} & $\mathrm{~V}$ & & $-0.0385(1)$ & $4.97(5)$ & 4.98 \\
\hline & ${ }^{51} \mathrm{~V}$ & $7 / 2$ & -0.038 & & \\
\hline \multirow[t]{2}{*}{24} & $\mathrm{Cr}$ & & $0.3532(10)$ & $1.90(3)$ & 3.1 \\
\hline & ${ }^{52} \mathrm{Cr}$ & 0 & 0.490 & 0 & \\
\hline 25 & $\mathrm{Mn}$ & $5 / 2$ & $-0.373(2)$ & $0.6(2)$ & 13.2 \\
\hline \multirow[t]{5}{*}{26} & $\mathrm{Fe}$ & & $0.954(6)$ & $0.22(16)$ & 2.53 \\
\hline & ${ }^{54} \mathrm{Fe}$ & 0 & 0.42 & 0 & \\
\hline & ${ }^{56} \mathrm{Fe}$ & 0 & 1.01 & 0 & \\
\hline & ${ }^{57} \mathrm{Fe}$ & $1 / 2$ & 0.23 & & \\
\hline & ${ }^{58} \mathrm{Fe}$ & 0 & $1.54(68)$ & & \\
\hline 27 & Co & $7 / 2$ & $0.278(4)$ & $5.22(8)$ & 37 \\
\hline \multirow[t]{6}{*}{28} & $\mathrm{Ni}$ & & $1.03(1)$ & $5.0(6)$ & 4.8 \\
\hline & ${ }^{58} \mathrm{Ni}$ & 0 & 1.44 & 0 & \\
\hline & ${ }^{60} \mathrm{Ni}$ & 0 & 0.28 & 0 & \\
\hline & ${ }^{61} \mathrm{Ni}$ & $3 / 2$ & 0.76 & & \\
\hline & ${ }^{62} \mathrm{Ni}$ & 0 & -0.87 & 0 & \\
\hline & ${ }^{64} \mathrm{Ni}$ & 0 & -0.037 & 0 & \\
\hline \multirow[t]{3}{*}{29} & $\mathrm{Cu}$ & & $0.7689(6)$ & $0.51(4)$ & 3.77 \\
\hline & ${ }^{63} \mathrm{Cu}$ & $3 / 2$ & 0.67 & & \\
\hline & ${ }^{15} \mathrm{Cu}$ & $3 / 2$ & 1.11 & & \\
\hline \multirow[t]{4}{*}{30} & $\mathrm{Zn}$ & & $0.5686(3)$ & $0.08(1)$ & 1.10 \\
\hline & ${ }^{64} \mathrm{Zn}$ & 0 & 0.55 & 0 & \\
\hline & ${ }^{66} \mathrm{Zn}$ & 0 & 0.63 & 0 & \\
\hline & ${ }^{68} \mathrm{Zn}$ & 0 & 0.67 & 0 & \\
\hline 31 & $\mathrm{Ga}$ & & 0.72 (1) & $<0.5$ & 2.80 \\
\hline 32 & $\mathrm{Ge}$ & & $0.81858(36)$ & $<0.2$ & 2.45 \\
\hline 33 & As & $3 / 2$ & $0.673(2)$ & $<1.6$ & 4.3 \\
\hline 34 & $\mathrm{Se}$ & & 0.795 (4) & 0.27 & 12.3 \\
\hline 35 & $\mathrm{Br}$ & & $0.677(2)$ & $<0.5$ & 6.7 \\
\hline 36 & $\mathrm{Kr}$ & & $0.791(15)$ & & 31 \\
\hline \multirow[t]{2}{*}{37} & $\mathrm{Rb}$ & & $0.708(2)$ & $<0.4$ & 0.7 \\
\hline & ${ }^{85} \mathrm{Rb}$ & $5 / 2$ & 0.83 & & \\
\hline 38 & $\mathrm{Sr}$ & & 0.69 (1) & 4.0 & 1.21 \\
\hline 39 & $\mathrm{Y}$ & $1 / 2$ & $0.775(2)$ & $0.15(1)$ & 1.31 \\
\hline 40 & $\mathrm{Zr}$ & & $0.70(1)$ & $<0.3$ & 0.18 \\
\hline 41 & $\mathrm{Nb}$ & $9 / 2$ & $0.7050(3)$ & $0.0063(6)$ & 1.15 \\
\hline 42 & Mo & & $0.695(7)$ & $<0.6$ & 2.7 \\
\hline 43 & ${ }^{99} \mathrm{Tc}$ & $9 / 2$ & $0.68(3)$ & & 122 \\
\hline 44 & $\mathrm{Ru}$ & & $0.721(7)$ & $<0.1$ & 2.56 \\
\hline 45 & $\mathrm{Rh}$ & $1 / 2$ & 0.588 (4) & 1.2 & 156 \\
\hline 46 & $\mathrm{Pd}$ & & 0.60 & $0.093(9)$ & 8.0 \\
\hline
\end{tabular}

instrument at NBS and the other on the theory, that will provide some background.

\section{Instrument}

The SANS instrument at the National Bureau of Standards is described in detail elsewhere [2]; however, a schematic of the major components is shown in figure 1 . The characteristics of the SANS instrument are given in table 2 . The wavelength, $\lambda$, can be varied from 0.4 to $1.0 \mathrm{~nm}$ by selecting the appropriate speed of a rotating helical-channel velocity selector. This is particularly important in beam broadening experiments because the wavelength 
Table 1 (Continued)

\begin{tabular}{|c|c|c|c|c|c|}
\hline $\begin{array}{l}\text { Atomic } \\
\text { number }\end{array}$ & $\begin{array}{l}\text { Element } \\
\text { or } \\
\text { isotope }\end{array}$ & $\begin{array}{l}\text { Nucl. } \\
\text { spin }\end{array}$ & $\begin{array}{l}\text { Scattering length } \\
\quad b\left(10^{-12} \mathrm{~cm}\right)\end{array}$ & $\begin{array}{c}\text { Incoherent } \\
\text { scattering cross-section } \\
\sigma_{\text {inc }}(\text { barn })\end{array}$ & $\begin{array}{c}\text { Absorption } \\
\text { cross section for } \lambda=1.8 \AA \\
\sigma_{\text {abs }}(\text { barn })\end{array}$ \\
\hline \multirow[t]{3}{*}{47} & $\mathrm{Ag}$ & & $0.602(2)$ & $0.49(4)$ & 63 \\
\hline & ${ }^{107} \mathrm{Ag}$ & $1 / 2$ & 0.83 & & \\
\hline & ${ }^{109} \mathrm{Ag}$ & $1 / 2$ & 0.43 & & \\
\hline \multirow[t]{2}{*}{48} & $\mathrm{Cd}$ & & $0.37+0.16 i$ & & 2450 \\
\hline & ${ }^{113} \mathrm{Cd}$ & $1 / 2$ & $-1.5+1.2 i$ & & 20000 \\
\hline 49 & In & & $0.408(4)$ & & 196 \\
\hline \multirow[t]{8}{*}{50} & Sn & & $0.6223(4)$ & $0.022(5)$ & 0.625 \\
\hline & ${ }^{116} \mathrm{Sn}$ & 0 & 0.58 & 0 & \\
\hline & ${ }^{117} \mathrm{Sn}$ & $1 / 2$ & 0.64 & & \\
\hline & ${ }^{118} \mathrm{Sn}$ & 0 & 0.58 & 0 & \\
\hline & ${ }^{119} \mathrm{Sn}$ & $1 / 2$ & 0.60 & & \\
\hline & ${ }^{120} \mathrm{Sn}$ & 0 & 0.64 & 0 & \\
\hline & ${ }^{122} \mathrm{Sn}$ & 0 & 0.55 & 0 & \\
\hline & ${ }^{124} \mathrm{Sn}$ & 0 & 0.59 & 0 & \\
\hline 51 & $\mathrm{Sb}$ & & $0.5641(12)$ & $0.17(12)$ & 5.7 \\
\hline \multirow[t]{5}{*}{52} & $\mathrm{Te}$ & & $0.543(4)$ & $0.6(4)$ & 4.7 \\
\hline & ${ }^{120} \mathrm{Te}$ & 0 & 0.52 & 0 & \\
\hline & ${ }^{123} \mathrm{Te}$ & $1 / 2$ & 0.57 & & \\
\hline & ${ }^{124} \mathrm{Te}$ & 0 & 0.55 & 0 & \\
\hline & ${ }^{125} \mathrm{Te}$ & $1 / 2$ & 0.56 & & \\
\hline 53 & I & $5 / 2$ & $0.528(2)$ & $\sim 0$ & 7.0 \\
\hline 54 & $\begin{array}{l}\mathrm{Xe} \\
{ }^{135} \mathrm{Xe}\end{array}$ & & $0.488(3)$ & & $\begin{array}{l}74 \\
2.7 \times 10^{6}\end{array}$ \\
\hline 55 & Cs & $7 / 2$ & $0.542(2)$ & 4.6 & 29 \\
\hline 56 & $\mathbf{B a}$ & & $0.528(5)$ & 2.5 & 1.2 \\
\hline \multirow[t]{2}{*}{57} & $\mathrm{La}$ & & $0.827(5)$ & $1.87(17)$ & 9.3 \\
\hline & ${ }^{139} \mathrm{La}$ & $7 / 2$ & 0.83 & & \\
\hline \multirow[t]{3}{*}{58} & $\mathrm{Ce}$ & & $0.483(4)$ & $\sim 0$ & 0.77 \\
\hline & ${ }^{140} \mathrm{Ce}$ & 0 & 0.47 & 0 & \\
\hline & ${ }^{142} \mathrm{Ce}$ & 0 & 0.45 & 0 & \\
\hline 59 & $\operatorname{Pr}$ & $5 / 2$ & $0.445(5)$ & 1.6 & 11.6 \\
\hline \multirow[t]{4}{*}{60} & $\mathrm{Nd}$ & & $0.780(7)$ & $11(2)$ & 46 \\
\hline & ${ }^{142} \mathrm{Nd}$ & 0 & 0.77 & 0 & \\
\hline & ${ }^{144} \mathrm{Nd}$ & 0 & 0.28 & 0 & \\
\hline & ${ }^{146} \mathrm{Nd}$ & 0 & 0.87 & 0 & \\
\hline \multirow[t]{4}{*}{62} & $\mathrm{Sm}$ & & & & 5600 \\
\hline & ${ }^{149} \mathrm{Sm}$ & $7 / 2$ & $-1.9+4.5 i$ & & 41000 \\
\hline & ${ }^{152} \mathrm{Sm}$ & 0 & -0.5 & 0 & 210 \\
\hline & ${ }^{154} \mathrm{Sm}$ & 0 & 0.96 & 0 & 5.5 \\
\hline \multirow[t]{2}{*}{63} & $\mathrm{Eu}$ & & 0.68 & & 4300 \\
\hline & ${ }^{153} \mathrm{Eu}$ & $5 / 2$ & & & 450 \\
\hline \multirow[t]{3}{*}{64} & $\mathrm{Gd}$ & & 1.5 & & 49000 \\
\hline & ${ }^{157} \mathrm{Gd}$ & $3 / 2$ & $4.3+4 i$ & & $\sim 254000$ \\
\hline & ${ }^{160} \mathrm{Gd}$ & 0 & 0.91 & 0 & 0.77 \\
\hline 65 & $\mathrm{~Tb}$ & $3 / 2$ & $0.738(3)$ & & 46 \\
\hline
\end{tabular}

dependency of the neutron scattering is a necessary part of the analysis. Longer wavelengths are also useful in diffraction measurements where larger sizes $(>0.5 \mathrm{~nm})$ of particles or voids are being examined and when multiple Bragg scattering from the crystal structure of the material is to be avoided. A cold source is important in SANS facilities because measurements can be obtained at higher wavelengths in a reasonable time interval. The function of a cold source is to lower the neutron thermal equilibrium temperature in the reactor, which shifts the peak intensity to higher wavelengths. Therefore $\lambda$ values of 1.5 to $1.8 \mathrm{~nm}$ can be used routinely and data can be collected at $\lambda=1.0 \mathrm{~nm}$ more quickly. The SANS facility at NBS is adding a cold source and will increase the power of the reactor to $20 \mathrm{MW}$ (June 
Table 1 (Continued)

\begin{tabular}{|c|c|c|c|c|c|}
\hline $\begin{array}{l}\text { Atomic } \\
\text { number }\end{array}$ & $\begin{array}{l}\text { Element } \\
\text { or } \\
\text { isotope }\end{array}$ & $\begin{array}{l}\text { Nucl. } \\
\text { spin }\end{array}$ & $\begin{array}{l}\text { Scattering length }{ }^{\mathrm{a}} \\
\quad b\left(10^{-12} \mathrm{~cm}\right)\end{array}$ & $\begin{array}{c}\text { Incoherent } \\
\text { scattering cross-section } \\
\sigma_{\text {inc }}(\text { barn })\end{array}$ & $\begin{array}{c}\text { Absorption } \\
\text { cross section for } \lambda=1.8 \AA \\
\sigma_{\text {abs }}(\text { barn })\end{array}$ \\
\hline \multirow[t]{6}{*}{66} & Dy & & $1.71(3)$ & & 950 \\
\hline & ${ }^{160} \mathrm{Dy}$ & 0 & 0.67 & 0 & 55 \\
\hline & ${ }^{161} \mathrm{Dy}$ & $5 / 2$ & 1.03 & & 585 \\
\hline & ${ }^{162} \mathrm{Dy}$ & 0 & -0.14 & 0 & 200 \\
\hline & ${ }^{163} \mathrm{Dy}$ & $5 / 2$ & 0.50 & & 140 \\
\hline & ${ }^{164} \mathrm{Dy}$ & 0 & 4.94 & 0 & 2300 \\
\hline 67 & Ho & $7 / 2$ & $0.85(2)$ & 4 & 65 \\
\hline 68 & $\mathrm{Er}$ & & $0.803(3)$ & 7 & 173 \\
\hline 69 & $\mathrm{Tm}$ & $1 / 2$ & $0.705(5)$ & & 127 \\
\hline 70 & $\mathrm{Yb}$ & & $1.262(12)$ & & 37 \\
\hline 71 & $\mathrm{Lu}$ & & $0.73(2)$ & & 112 \\
\hline 72 & Hf & & $0.777(14)$ & & 105 \\
\hline 73 & $\mathrm{Ta}$ & & $0.691(7)$ & $0.020(4)$ & 21 \\
\hline \multirow[t]{5}{*}{74} & W & & $0.477(5)$ & $1.86(12)$ & 19.2 \\
\hline & ${ }^{182} \mathrm{~W}$ & 0 & 0.83 & 0 & \\
\hline & ${ }^{183} \mathrm{~W}$ & $1 / 2$ & 0.43 & & \\
\hline & ${ }^{184} \mathrm{~W}$ & 0 & 0.76 & 0 & \\
\hline & ${ }^{186} \mathrm{~W}$ & 0 & -0.12 & 0 & \\
\hline 75 & $\operatorname{Re}$ & & 0.92 & & 86 \\
\hline \multirow[t]{5}{*}{76} & Os & & 1.08 & 0.5 & 15.3 \\
\hline & ${ }^{188}$ Os & 0 & 0.78 & 0 & \\
\hline & ${ }^{189} \mathrm{Os}$ & $3 / 2$ & 1.10 & & \\
\hline & ${ }^{190} \mathrm{Os}$ & 0 & 1.14 & 0 & \\
\hline & ${ }^{192} \mathrm{Os}$ & 0 & 1.19 & 0 & \\
\hline 77 & Ir & & $1.06(2)$ & & 440 \\
\hline 78 & $\mathrm{Pt}$ & & $0.95(3)$ & $0.60(4)$ & 8.8 \\
\hline 79 & $\mathrm{Au}$ & $3 / 2$ & $0.763(6)$ & $0.36(4)$ & 98.8 \\
\hline 80 & $\mathrm{Hg}$ & & $1.266(2)$ & 6 & 375 \\
\hline 81 & $\mathrm{Tl}$ & & $0.889(2)$ & 0.1 & 3.4 \\
\hline 82 & $\mathrm{~Pb}$ & & $0.94003(14)$ & $0.0013(5)$ & 0.17 \\
\hline \multirow[t]{2}{*}{87} & $\mathrm{Bi}$ & $9 / 2$ & $0.8495(12)$ & $0.0072(6)$ & 0.036 \\
\hline & & & $0.85256(14)$ & & \\
\hline 90 & ${ }^{232} \mathrm{Th}$ & 0 & $1.008(4)$ & 0 & 7.56 \\
\hline 91 & ${ }^{231} \mathrm{~Pa}$ & & 1.3 & & 200 \\
\hline \multirow[t]{3}{*}{92} & $\mathrm{U}$ & & $0.861(4)$ & & 7.68 \\
\hline & ${ }^{235} \mathrm{U}$ & $7 / 2$ & 0.98 & & 694 \\
\hline & ${ }^{238} \mathrm{U}$ & 0 & 0.85 & 0 & 2.71 \\
\hline 93 & ${ }^{237} \mathrm{~Np}$ & & 1.06 & & 170 \\
\hline \multirow[t]{3}{*}{94} & ${ }^{239} \mathrm{Pu}$ & & 0.75 & & 1026 \\
\hline & ${ }^{240} \mathrm{Pu}$ & 0 & 0.35 & 0 & 295 \\
\hline & ${ }^{242} \mathrm{Pu}$ & 0 & 0.81 & 0 & \\
\hline 95 & ${ }^{243} \mathrm{Am}$ & $5 / 2$ & 0.76 & & \\
\hline 96 & ${ }^{244} \mathrm{Cm}$ & 0 & 0.7 & 0 & \\
\hline
\end{tabular}

${ }^{a}$ Coherent scattering lengths for the eiements are mostly best values recommended by Koester (1977). Complex scattering lengths relate to $\lambda=1 \AA$. All entries without quoted errors are to be considered with caution as their accuracy is uncertain. Incoherent scattering cross sections for nuclei with zero spin have been set equal to zero.

1984). Both of these additions will increase the neutron flux at the sample significantly and will result in shorter measurement times.

There are two types of collimating apertures which define the beam direction and divergence. One type consists of a pair of cadmium pin hole irises, one after the velocity selector and another before the sample chamber. The other collimation system is for higher resolution measurements and consists of a set of channels in cadmium masks which effectively converge the neutron beam to a point at the center of the detector. The multiple sample chamber is computer controlled and can be used under vacuum. Single samples can be studied as a function of temperature from 12 to $1600 \mathrm{~K}$. Horizontal and vertical field electromagnets are also available. Sample 


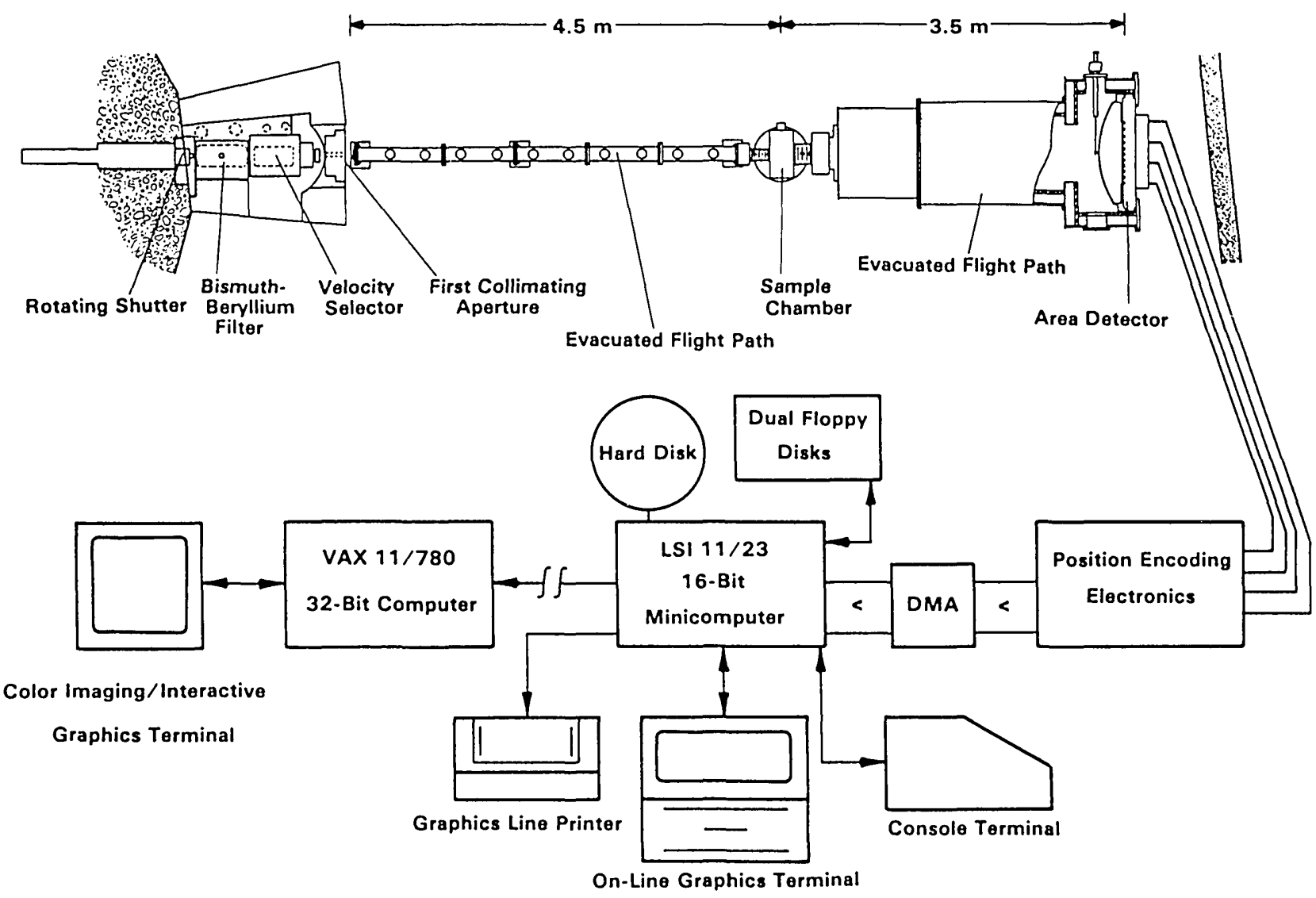

Figure 1-A diagram of the NBS small angle neutron scattering facility including computer capabilities (Ref. [2] is source).

Table 2. Characteristics of the SANS instrument at $10 \mathrm{MW}$ reactor power

Wavelength:

Collimation:

Variable from 0.48 to $1.0 \mathrm{~nm}, \Delta \lambda / \lambda=0.25$

Minimum Q:

$Q$ range:

Sample size:

Single pair of circular irises or 7 to 9 channel converging beam collimation

$0.006 \AA^{-1}$ at $\lambda=0.6 \mathrm{~nm} ; 0.004 \AA^{-1}$ at $\lambda=0.9 \mathrm{~nm}$ $0.004 \AA^{-1}$ to $0.5 \AA^{-1}$

0.4 to $2.0 \mathrm{~cm}$ pin-hole collimation; $1.6 \mathrm{~cm} \times 1.6$ $\mathrm{cm}$ or $2.2 \mathrm{~cm}$ diameter-converging collimation 1-30 mm thickness (uniform)

Flux at sample: $\quad 10^{4}$ to $2 \times 10^{5} \mathrm{n} / \mathrm{cm}^{2}$-sec depending on slit sizes and wavelength

Detector:

$64 \mathrm{~cm} \times 64 \mathrm{~cm}$ position sensitive counter with $8 \times 8 \mathrm{~mm}^{2}$ resolution

sizes are usually 1.0 to $2.5 \mathrm{~cm}$ in diameter and 2 to 30 $\mathrm{mm}$ thick. Uniform thickness is essential for analyzing the results. The scattered neutrons are detected on a $64 \mathrm{~cm} \times 64 \mathrm{~cm}$ position-sensitive proportional counter with a spatial resolution of $8 \mathrm{~mm}$ in each direction and is divided into 128 columns and 128 rows. A dedicated minicomputer processes the signals from the detector and stores the data. The data are recorded on floppy disks for archival storage and are transferred to a larger computer for analysis, and they can be viewed on an interactive color graphics terminal as well. The angle between the incident beam and the scattered beam is the scattering angle, $\epsilon$, (see fig. 2). The magnitude of the scattering vector $Q$ is $(4 \pi / \lambda) \sin \epsilon / 2$ which is approximated $2 \pi \epsilon / \lambda$ in the small angle limit.

\section{Theory}

This section is a very brief discussion of some of the theoretical considerations that are particularly germane to ceramics applications of SANS. Excellent reviews [3-5] of SANS formalism and practice exist for the interested reader.

The nature of small angle scattering from a monodisperse population of spherical particles or voids is determined by the phase shift $\rho$ that a plane wave suffers in traversing a single particle;

$$
\rho=(4 \pi / \lambda) \Delta n R,
$$

where $\lambda$ is the neutron wavelength, $R$ is the particle radius, and 


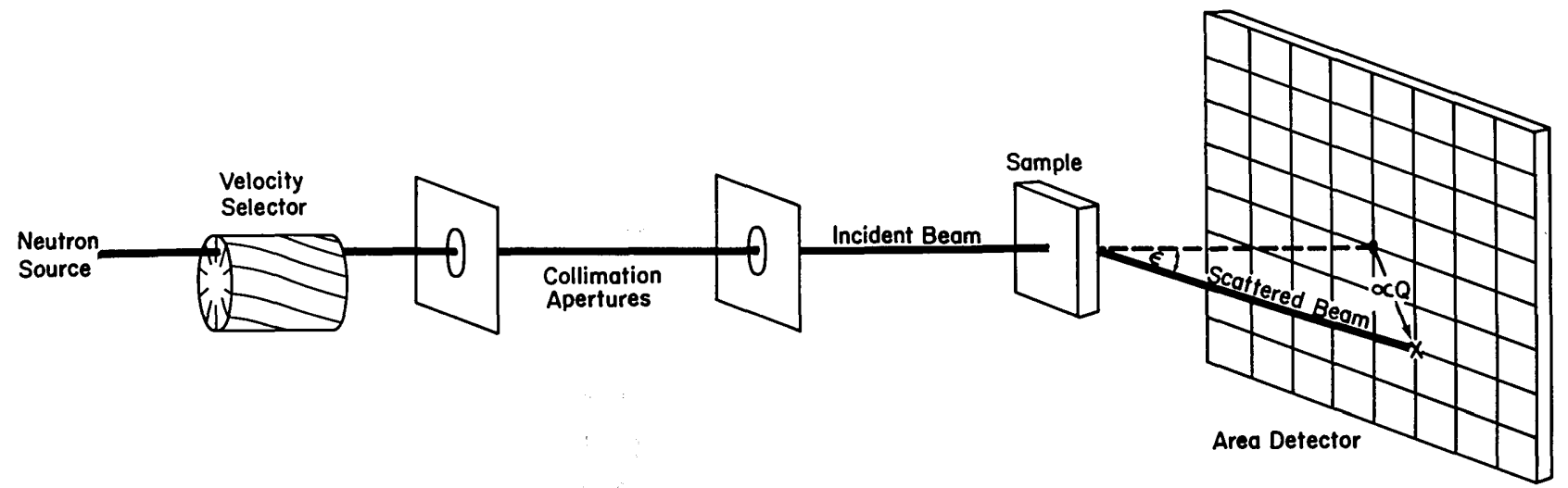

Figure 2-A schematic diagram of key components used for the small angle scattering measurements.

$$
\Delta n=\Delta b \lambda^{2} / 2 \pi
$$

is the index of refraction of the particle or void relative to the matrix medium, which is assumed to be homogeneous and thus, acting alone, to produce no angular divergence in the neutron beam. In eq (2), $\Delta b$ is the relative scattering length density or contrast of the particle (or void) with that of the matrix material:

$$
\Delta b=\Sigma_{\text {cell }} b_{i} / V_{\text {cell }}-b_{\text {matrix }}
$$

where the sum is over the coherent scattering lengths $b_{i}$ of the material formula unit for a crystalline unit cell, $V_{\text {cell }}$ is the unit cell volume, and where $b_{\text {matrix }}$ is defined by the analogous average for the matrix material. Thus combining eqs (1) and (2) the phase shift parameter $\rho$ can be written in the useful form

$$
\rho=2 \Delta b R \lambda
$$

which shows the three independent factors on which it depends: 1) material contrast $\Delta b, 2$ ) particle size $2 R$, and, 3) neutron wavelength $\lambda$.

In the limit of small phase shift, $\rho<<1$, singleparticle scattering is described by the Born approximation, or equivalently, the Rayleigh-Gans model, which in SANS is identified with small angle diffraction. In this limit the neutron differential crosssection-i.e., the relative probability for scattering into angle $\epsilon$ which is equal to $2 \theta$-is exactly expressed as the Fourier transform of the single-particle density self-correlation function, which is sensitive to the details of particle shape and size. The diffractive regime theory and measurement are usually described in terms of the scattering wavevector

$$
\mathbf{Q}=2 \pi \epsilon / \lambda,
$$

which absorbs all of the $\lambda$-dependence of the scattering; in particular the width of the scattering in the Q-representation is inversely proportional to particle radius but independent of $\lambda$, so that in the angular representation, the root mean square, rms, angular deviation of scattered neutrons is proportional to $\lambda$ and is inversely proportional to the particle radius. Moreover, as $\rho$ approaches zero, the singleparticle total cross-section $\sigma$,-i.e., the integral of the differential cross-section over all angles-becomes proportional to the particle geometrical cross-sectional area multiplied by $\rho^{2}$ and thus also tends rapidly to zero. As a result, the mean-free-path length

$$
l=1 / D \sigma,
$$

where $D$ is the number of scatterers per unit volume, becomes much larger than sample dimensions-except for very dense systems or for very thick samples. This has two important (related) consequences: 1) the relative probability for scattering becomes small so that the observed intensity is the sum of an unscattered "incident" beam, broadened only by instrumental resolution, and a much weaker scattered beam which contains the particle size and shape information; and 2) incident neutrons effectively have only one opportunity to be scattered by individual particles while traversing the sample so that the scattered component of the observed neutron intensity is simply the $N$-fold multiplication of the single-particle scattering from $N$ particles-i.e., contributions from multiple scattering and coherent interparticle interference are negligible. (We simply note here that interparticle interference can be an important effect in small angle diffraction from dense systems of scattering particles or voids.) Typically, the diffractive regime is considered to apply to particles of radius less than $0.1 \mu \mathrm{m}$, and $\sigma=\pi R^{2} \rho^{2} / 2$. 
In the opposite limit, $\rho>>1$, the scattering from a single particle is well described by ray optics with each particle refracting neutrons as a lens. In this regime the rms angular deviation of the neutron beam produced by a particle is independent of its size and determined only by the relative index of refraction which, recalling eq (2), is proportional to $\lambda^{2}$. Moreover, the total cross-section $\sigma$ approaches the geometrical limit $2 \times$ cross-sectional area $\left(\sigma=2 \pi R^{2}\right)$, so that the mean-free-path length becomes comparable to the average interparticle spacing. In probabilistic terms every particle scatters, and as a result: 1) the observed intensity is not separable into an unscattered "incident-beam" and a weak, scattered part-in effect the incident beam is broadened beyond instrumental resolution without "residual" scattering; and 2) multiple scattering effects dominate this "beam broadening" which means that the particle size influences the measurement indirectly-but substantially-through its influence on the macroscrupic configuration of scatterers (e.g., the mean particle spacing for fixed volume fraction). Generally, the refractive regime is reached by particles larger than $10 \mu \mathrm{m}$.

For intermediate values of the phase shift, $\rho \sim 1$, the scattering is not well described in terms of either limiting case or as a simple combination of diffractive and refractive effects. A plot of $\sigma / \pi R^{2}$ vs $\rho$ in figure 3 suggests the effective extent of the intermediate or "cross-over" $\rho$-regime connecting these extremal behaviors. The diffractive regime is confined to the immediate neighborhood of the origin while the refractive asymptote, defined by the dotted line, is approached only slowly for large $\rho$. In work described elsewhere [6] we have developed a synthesis of a general formal expression for the single-particle scattering cross-section, for unrestricted $\rho$, as derived by Weiss [7] with the multiple-scattering formalism of Snyder and Scott [8], modified for the relevant "pinhole" geometry of the typical SANS instrument. We find that for $\rho \sim 1$, the relevant regime for many ceramics applications, the predicted neutron intensity as a function of scattering angle is approximately Gaussian, an informal characteristic of multiplescattering phenomena, with a standard deviation estimated by $\Delta \epsilon$

$$
\Delta \epsilon=[T / l(\lambda)]^{1 / 2} \epsilon_{0}(\lambda)
$$

where $T$ is the sample thickness, $l$ is the mean-free-path length as defined in eq (6), and $\epsilon_{0}$ is a measure of the rms angular deviation produced by a single particle. In eq (7) we have indicated the implicit wavelength

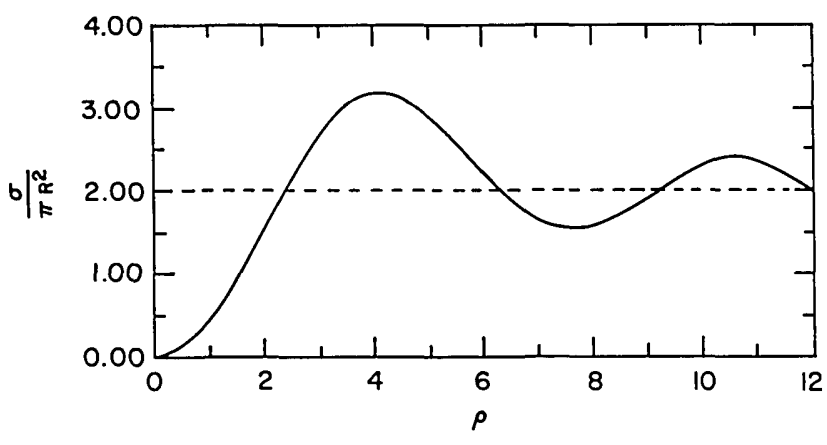

Figure 3-The oscillatory variation of the total neutron cross-section scattering $\sigma$ as a function of the phase shift $\rho$. In the multiple refraction limit $\rho=2 \pi R^{2}$ (Ref. [7] is source).

dependence since a plot of measured $\Delta \epsilon$ vs $\lambda$ is the most effective means of determining the nature of beam broadening. In this regime $l$ is inversely proportional to $\lambda^{2}$ and $\epsilon_{0}$ is approximately linear in $\lambda$ (the $\epsilon_{0}$ behavior thus suggesting the approach to the single-particle diffractive limit), so that the overall variation of $\Delta \epsilon$ is approximately quadratic in $\lambda$. A similar expression applies to the refractive regime, $\rho>>1$, where $l$ becomes independent of $\lambda$ while $\epsilon_{0}$ varies approximately as $\lambda^{2}$, thus giving $\Delta \epsilon$ a similar wavelength dependence as for $\rho \sim 1$ but one that arises from a different "mechanism" and which depends in a very different way on $R$. An application to experiment is discussed below.

\section{Experiment}

Diffraction and beam broadening measurements are quite different and are usually obtained in different configurations of the SANS instrument. Diffraction experiments probe for microstructural phenomena in the range of 1 to $100 \mathrm{~nm}$. The SANS detector is usually located directly behind the sample so that the incident beam is centered in the middle of the detector. The experiment generally requires 6 to 12 hours and a beamstop is used to eliminate scattering from the incident beam. Sample thickness ( 2 to $6 \mathrm{~mm}$ ) is kept small to minimize multiple scattering effects. Absorption and incoherent neutron scattering should be reduced for best results in most SANS experiments with ceramic materials.

The beam broadening effect is wavelength $(\lambda)$ dependent and the resulting widths are most sensitive to $\lambda$ at $\lambda$ greater than $0.7 \mathrm{~nm}$. Typical experiments require only 3 minutes to 2 hours depending on $\lambda$, the void or particle size, density and thickness of the sample and are similar to transmission measurements. 
It is important to determine the exact center of the neutron scattering; therefore, the incident beam is set off to one side of the detector without a beamstop. This can be done without harming the detector because the peak intensity is greatly reduced in the broadened state. Cadmium foil can be used to reduce the scattered beam intensity over the entire detector to further ensure the safety of the detector; nevertheless, care should be taken when obtaining data without a beamstop. The samples should be measured at three wavelengths or more for best results. Also thicker samples, 5 to $30 \mathrm{~mm}$, are desirable to increase the number of scattering events.

Hydrogen and $\mathbf{B}^{10}$ or naturally occurring boron are generally undesirable in elastic neutron scattering experiments so that deuterium and $\mathbf{B}^{11}$ are often substituted for these elements respectively. $\mathrm{B}^{10}$ absorbs neutrons and can be used to stop the chain reaction in nuclear reactors. Therefore SANS measurements of boron containing ceramic materials should have less than $10 \% \mathrm{~B}$ and be $3 \mathrm{~mm}$ or less in thickness. If these conditions are not possible then the materials can be made with $B^{11}$ which is relatively inexpensive and easy to obtain. Hydrogen has a large incoherent scattering component that reduces the signal-to-noise ratio in the data. Ceramic binders containing hydrogen and ceramics containing water are difficult to measure. Usually heavy water $\left(D_{2} 0\right)$ can be used if water is required in the sample. The coherent scattering lengths $(b)$, incoherent scattering cross-sections, and absorption cross-section values for the elements and isotopes can be found in table 1, taken from Kostorz [1]. It is worthwhile to avoid elements or isotopes with high neutron absorption or high incoherent scattering cross-section values.

\section{Diffraction Region}

Most SANS experiments are in the diffraction region and in ceramics are concerned with inhomogeneities such as voids, cavities, microcracks, precipitates, sintered porosity, inclusions, nucleation, and growth of second phases. In principle it is possible to determine quantitatively particle size, shape, size distribution, surface area and other microstructural values. Examples of SANS experiments with ceramic materials include the following: formation and growth of heterogeneities in glass by A. W. Wright [9], creep cavitation in sintered alumina by $\mathbf{R}$. A. Page and James Lankford [10], growth and coarsening of pure and doped $\mathrm{ZrO}_{2}$ by A. F. Wright, S. Nun and N. H. Brett [11], microcracks in sintered $\mathrm{YCrO}_{3}$ by E. D.
Case and C. Glinka [12], and $\mathrm{Fe}$ and $\mathrm{W}$ inclusions in hot pressed $\mathrm{Si}_{3} \mathrm{~N}_{4}$ by $\mathrm{K}$. Hardman-Rhyne, N. F. Berk and $N$. Tighe [13]. The results of the two last-named works will be discussed briefly.

It is preferable to have a two-component system such as the matrix material and precipitates or voids. One way to avoid multiple component systems is to run a control sample which was done in the $\mathrm{YCrO}_{3}$ microcrack experiment [12]. $\mathrm{YCrO}_{3}$ is a material which is sintered around $1750^{\circ} \mathrm{C}$, thereby establishing its microstructure (porosity, grain size, etc.) but which undergoes an apparent phase transition around $1100^{\circ} \mathrm{C}$. Thus if the material is quenched from above $1100^{\circ} \mathrm{C}$, microcracks as well as pores are present in the final material. However if the material is annealed at $1050^{\circ} \mathrm{C}$ the microcracks can heal and only the pores remain. Thus by subtracting the neutron scattering data of a healed $\mathrm{YCrO}_{3}$ sample from that of a microcracked sample, a third scattering distribution, due only to the microcracks in the material called $I_{\mathrm{DIFF}}$, can be obtained. These data are analyzed to determine several microstructural parameters.

Both SANS and elasticity measurements were collected on these samples which allowed the mean crack radius and crack number density to be calculated. The total surface area of the microcracks was estimated by using high $\mathbf{Q}$ data which was normalized to the scattering from water. Figure 4 shows the logarithmic function of $I_{\text {DIFF }}$ versus the scattering vector $\mathbf{Q}$. The solid line is a Porod [14] functional fit which describes the data at large

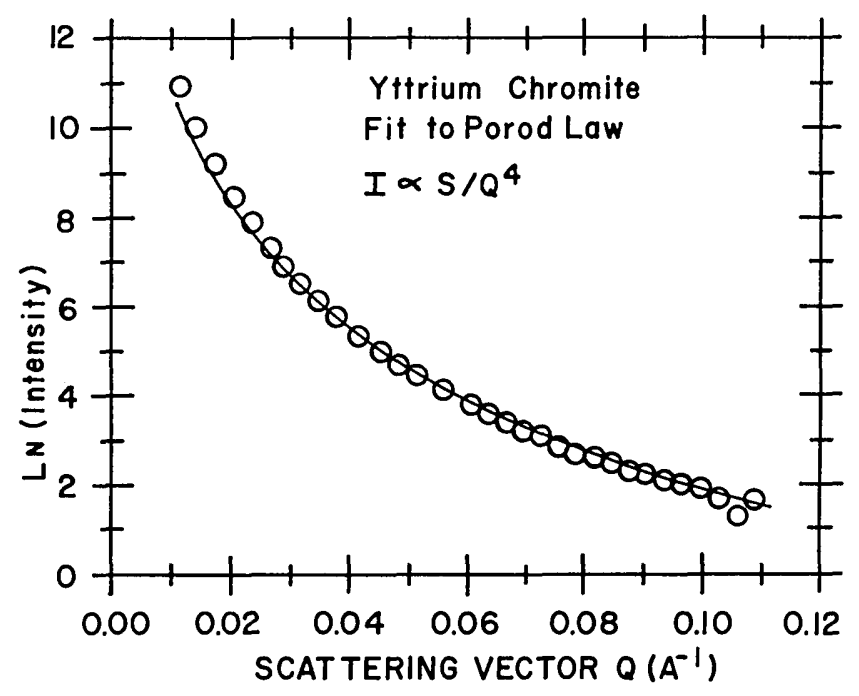

Figure 4-Open circles are the net scattering due to microcracks from a $7 \mathrm{~mm}$ thick specimen of $\mathrm{YCrO}_{3}$ plotted on a logarithmic scale versus the scattering vector $\mathbf{Q}$. The curve is a least-square fit of a Porod law (Ref. [12] is source). 
$\mathbf{Q}\left(\mathbf{Q}>0.03 \AA^{-1}\right)$ and can be expressed in the following form:

$$
I \alpha \frac{d \Sigma}{d \Omega} \sim \frac{2 \pi(\Delta b)^{2}}{V} \frac{S}{\mathbf{Q}^{4}}
$$

where $d \Sigma / d \Omega$ is the macroscopic cross-section, $V$ the sample volume seen by the neutron beam and $S$ the total surface area of the scattering centers.

Because the Porod function does not apply to low Q region, other functional forms of the scattering cross-section must be used. For sharp-edged, randomly oriented scattering centers of any given geometry, a Guinier [15] function can be used at small $\mathbf{Q}$ values;

$$
\frac{d \Sigma}{d \Omega} \sim(\Delta b)^{2} V_{p}^{2} \exp \left(-R_{G}^{2} \mathbf{Q}^{2} / 3\right)
$$

where $V_{p}$ is the volume of the particle (or scattering center) and $R_{G}$ is the particle's radius of gyration with respect to its center of gravity. However a better functional fit to the data can be obtained by assuming that the scattering from microcracks is modeled after randomly oriented thin disks [14] of thickness $2 \mathrm{H}$, diameter 2a;

$$
\frac{d \Sigma}{d \Omega}=\frac{V_{p}^{2} N_{p}^{2}(\Delta b)^{2}}{V} \frac{2}{\mathbf{Q}^{2} a^{2}} \exp \left(-\mathbf{Q}^{2} H^{2} / 3\right)
$$

where $N_{p}$ is the number of microcracks and $\mathbf{Q} H<1<<\mathbf{Q}$. This low $\mathbf{Q}$ fit to the data $\left(I_{\mathrm{DIFF}}\right)$ can be seen in figure 5 . Various microcrack parameters have been calculated and agree well with other similar parameters in the literature [12] and are as follows: crack number density $\left(4.7 \times 10^{8} \mathrm{~cm}^{-3}\right)$, surface area $(1.5$ $\mathrm{cm} \times 10^{3} \mathrm{~cm}$ ), crack aspect ratio $\left(1.5\right.$ to $\left.3.5 \times 10^{-3}\right)$, volume fraction $\left(2.6 \times 10^{-3}\right)$, and crack opening displacement $(250 \AA)$. The mean crack radius is 5.7 $\mu \mathrm{m}$ which corresponds well with the measured grain size of $6 \mu \mathrm{m}$ and is consistent with a model of localized stress induced microcracks.

Although optical and electron microscopy can identify small defects $(<10 \mu \mathrm{m})$ in advanced ceramic materials, SANS can quantify the size, shape and distribution of these defects in the bulk of the material. Hot pressed, $\mathrm{MgO}$ doped $\mathrm{Si}_{3} \mathrm{~N}_{4}$ is an example of a complementary study with SANS and transmission electron microscopy, TEM. TEM studies of this material clearly showed small, approximately spherical inclusions in $\mathrm{Si}_{3} \mathrm{~N}_{4}$ that were identified as $\mathrm{Fe}$ and $\mathrm{W}$. There was no evidence of pores, microcracks or

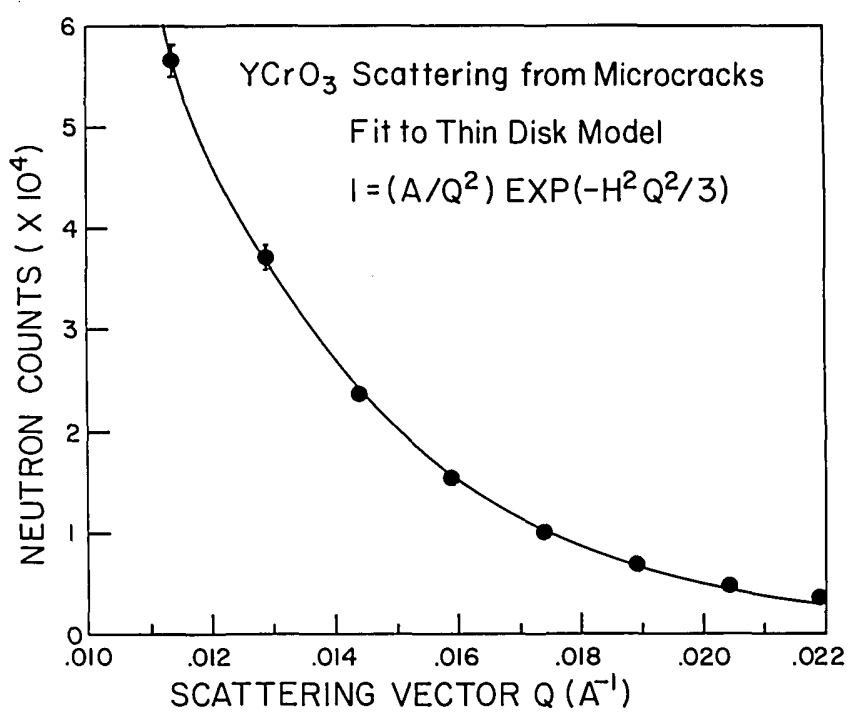

Figure 5-The data points are the low $\mathbf{Q}$ scattering from microcracks in a $7 \mathrm{~mm}$ thick specimen of $\mathrm{YCrO}_{3}$. The curve is a least-squares fit to the data of the scattering function for randomly oriented thin disks of thickness $2 \mathrm{H}$ (Ref. [12] is source).

microvoids from the TEM observations, but the sample had not been temperature treated where voids are more likely to appear.

Pores larger than $90 \mathrm{~nm}$ can be detected by examining transmission data collected at two or more wavelengths remembering that the higher wavelengths are more sensitive to porosity effects. Focussing collimation was used to examine the wavelength dependency of the neutron scattering as shown in figure 6 and no wavelength-dependent beam broadening was observed. This is consistent with observations from TEM and other characterization methods which suggest that this sample of $\mathrm{Si}_{3} \mathrm{~N}_{4}$ is fully dense with little or no porosity. Therefore we assume the SANS data reflect information relevant to the $\mathrm{Fe}$ and $\mathrm{W}$ inclusions that are present.

The small angle neutron scattering of the inclusions at $\lambda=0.9 \mathrm{~nm}$ is plotted as exponentially spaced intensity contour lines for the two dimensional detector (see fig. 7). There is a beamstop located in the center of the detector (solid circle) where the intensity is greatest and decreases as the distance away from the center increases. The intensity of the scattering is usually expressed as a function of $\mathbf{Q}$, given in units of inverse angstroms $\left(10 \AA=1 \mathrm{~nm}\right.$ and $\left.1 \AA^{-1}=10 \mathrm{~nm}^{-1}\right)$. Background and transmission corrections must be made to the raw data. Since the contour plot (fig. 7) indicates the scattering is isotropic we have circularly averaged the corrected data and plotted logarithm of intensity versus $Q$ for the $\mathrm{Fe}$ and $\mathrm{W}$ inclusions in $\mathrm{Si}_{3} \mathrm{~N}_{4}$ (see fig. 8). 


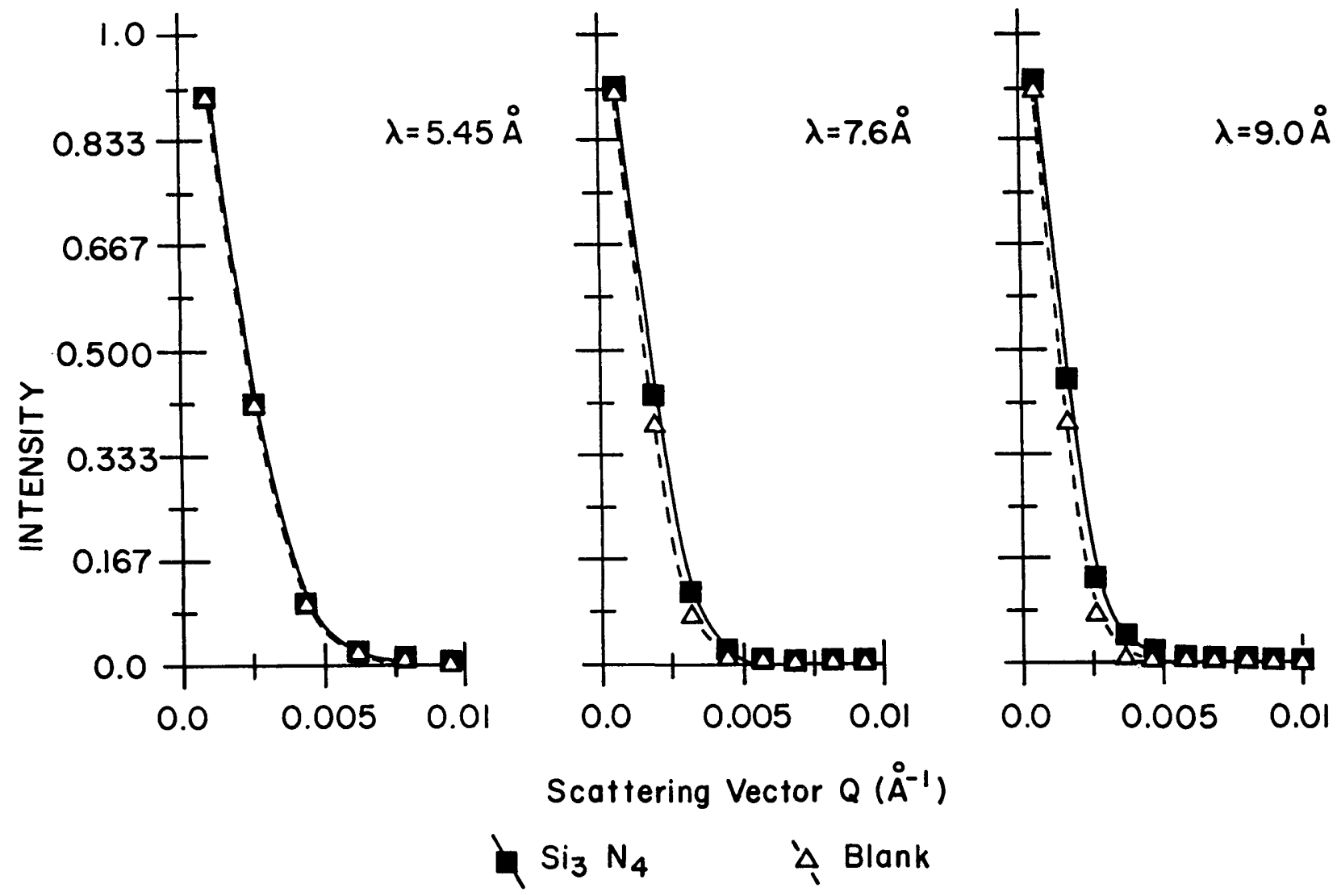

Figure 6-Comparison of direct beam scattering (blank sample) with the scattering from the $\mathrm{Si}_{3} \mathrm{~N}_{4}$ sample at several wavelengths.

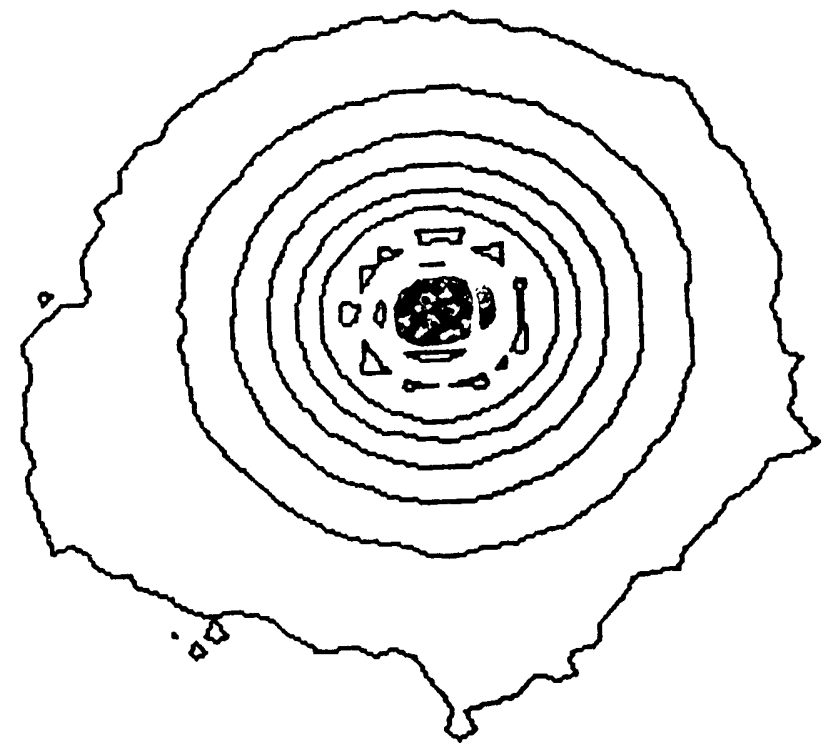

Figure 7-Exponentially spaced intensity contour plots from the twodimensional SANS detector of the $\mathrm{Si}_{3} \mathrm{~N}_{4}$ sample at $\lambda=0.9 \mathrm{~nm}$.

Most SANS analyses include one or both regions indicated in figure 8 . Often the intermediate region will be included in one of these regions or treated

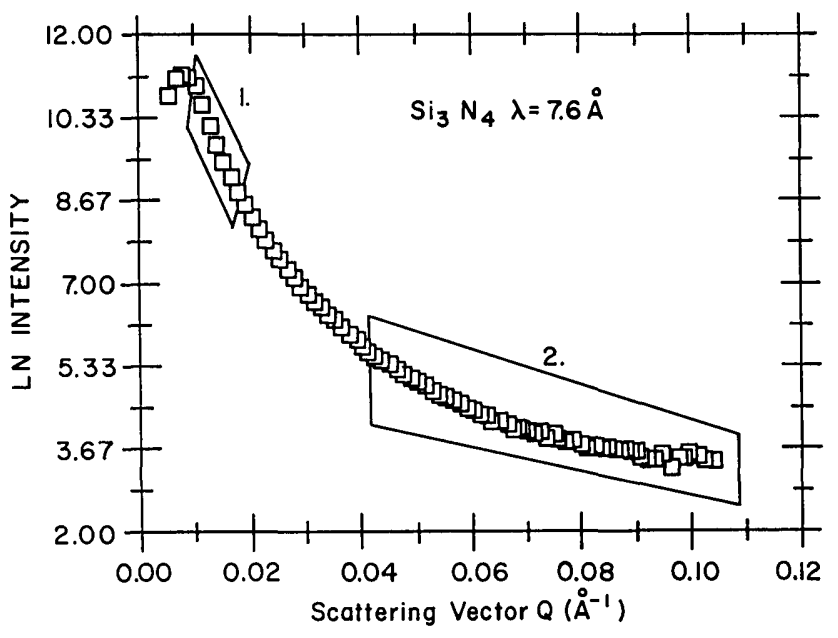

Figure 8-Logarithm of neutron scattering intensity of $\mathrm{Fe}$ and $\mathrm{W}$ inclusions in $\mathrm{Si}_{3} \mathrm{~N}_{4}$ versus scattering vector, $\mathbf{Q}$, in reciprocal angstroms. The two regions ( 1 and 2$)$ denote the Guinier and Porod regions, respectively.

separately as was the case in the thin disk model for $\mathrm{YCrO}_{3}$ microcracks. Region 1, shown in figure 8 and expanded in figure 9, is the Guinier region where the logarithm of the intensity has a $\mathbf{Q}^{2}$ behavior. $\mathbf{A}$ 


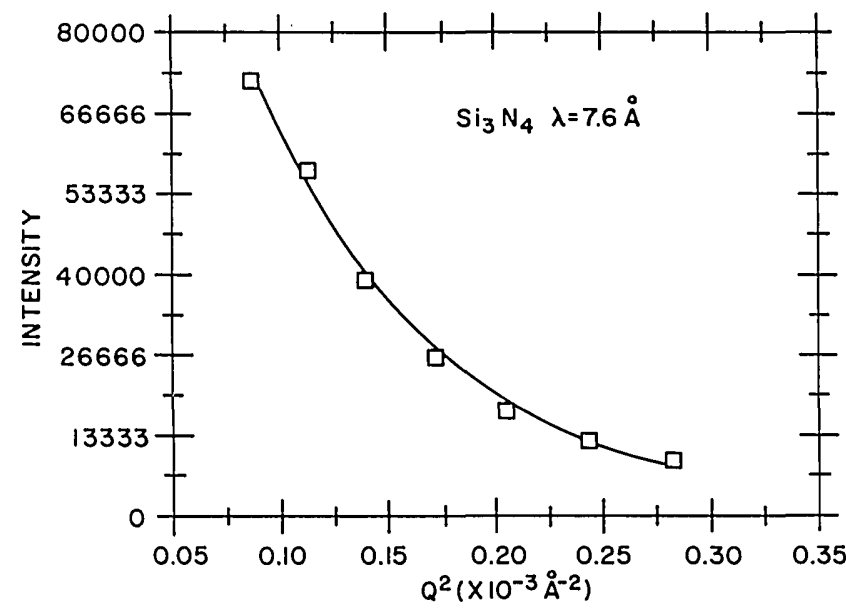

Figure 9-Plot of the Guinier fit (solid line) to the data (squares) at $\lambda=0.76 \mathrm{~nm}$.

Guinier fit (solid line in fig. 9) to the data (squares) at $\lambda=0.76 \mathrm{~nm}$ yields a radius of gyration (from eq (9)) of $18.6 \mathrm{~nm}$ which is related to the average radius of the $\mathrm{Fe}$ and $\mathrm{W}$ inclusions. If we assume the inclusions are monodispersed and spherical in shape, $R_{G}=(3 / 5)^{1 / 2} R_{S}$ so that the average particle radius is $24.0 \mathrm{~nm}$. In this scattering region the neutron intensity is limited by the larger dimensions of the scattering particles. The Guinier approximation is valid over a range of $\mathbf{Q}_{\mathrm{MAX}} R_{G} \leqslant 1.2$. In our case the maximum $\mathbf{Q}$ is $0.017 \AA$ and $\mathbf{Q}_{\mathrm{MAX}} R_{G} \sim 3$ which extends outside the Guinier approximation range although the logarithm of the intensity has $\mathbf{Q}^{2}$ behavior in this region.

Region 2 in figure 8 is called the Porod region and has a $\mathbf{Q}^{-4}$ dependence. The Porod region is more sensitive to smaller dimensions of the scattering centers and results in a characteristic Porod length which measures a surface to volume ratio if absolute intensities can be determined. Since the Porod region is valid for high $\mathbf{Q}$ values only, other similar functional forms have been used to extend the Porod region to lower $\mathbf{Q}$ values. One such form is the Debye et al. model [16] which assumes scattering from a two phase material. The particles or voids can be random in size, shape, and distribution throughout the material. The scattering cross-section from this model is given by

$$
\frac{d \Sigma}{d \Omega}=\frac{8 \pi V a^{3}(\Delta b)^{2}}{\left(1+\mathbf{Q}^{2} a^{2}\right)^{2}}
$$

The correlation length $a$ is equal to Porod's inhomogeneity length [14], $l_{p}=4 V / S$ where $V / S$ is the volume to surface ratio of the total interface separating the two phases. Thus, for a population of spheroidal particles $a$ is a characteristic of average particle size $\left(a=4 / 3 R_{S}\right)$. A Debye $e t$ al. fit (solid line) to the data (squares) at $\lambda=0.55 \mathrm{~nm}$ is shown in figure 10. The correlation length $a$ for the $\mathrm{Fe}$ and $\mathrm{W}$ inclusions in $\mathrm{Si}_{3} \mathrm{~N}_{4}$ is $21.2 \mathrm{~nm}$. A complicating factor in this study is the wide distribution of inclusion sizes and the difference in $\Delta b$ of $\mathrm{Fe}$ and $\mathrm{W}$.

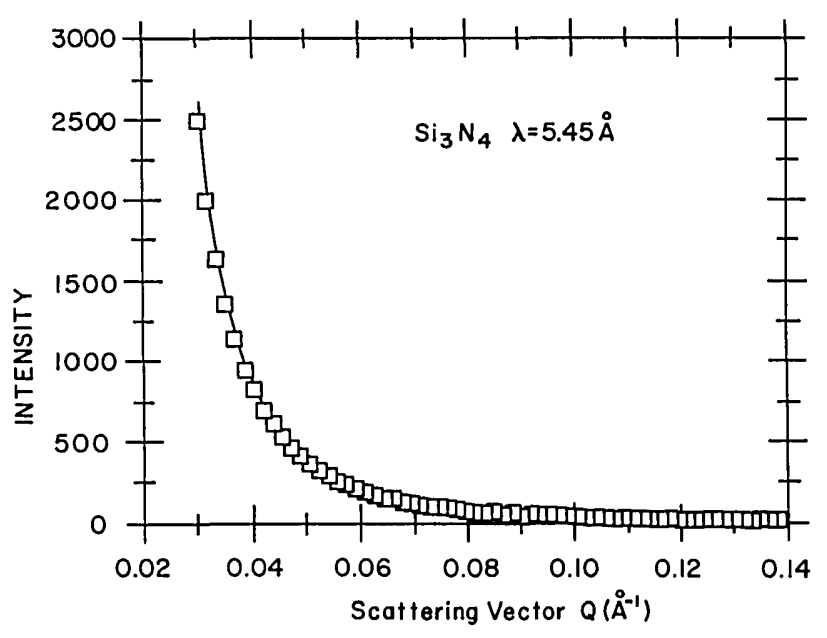

Figure 10-Plot of a Debye fit (solid line) to the data (squares) at $\lambda=0.55 \mathrm{~nm}$.

Further SANS diffraction experiments of distributed damage due to stress and temperature are expected as this technique becomes familiar in ceramic research. These results, coupled with failure tests, optical and electron microscopy, can help in understanding and improving the structural reliability of advanced ceramic materials.

\section{Multiple Refraction Region}

A few experiments have been published on multiple refraction effects in nonmagnetic materials, yet it remains unclear if these effects have been observed. Nevertheless, two papers discuss these phenomena in some detail. Weiss [7] studied the neutron beam broadening effect of several materials including bismuth, magnesium, and carbon black. Moreover he demonstrated the full width at half maximum as a function of scattering angle, called $\Delta \epsilon$, from neutron beam broadening depends on $T^{1 / 2}, \lambda^{2}, \Delta b$, and $s$, where $T$ is the thickness of the sample and $s$ is a parameter describing the particle or void shape, and is independent of $R$ the radius of the particle or void. The experimentally determined $\Delta \epsilon$ was compared to theoretical values obtained using the von Nardroff multiple scattering formula for spheres and for random 
surfaces [17]. The von Nardroff formula assumes the measured angular distribution to be Gaussian. But this is true only if the single particle scattering angle distribution falls off faster than Porod behavior $\left(\epsilon^{-4}\right)$, which generally is not the case. This is consistent with the behavior of the observed intensity which one approximates as Gaussian at small angles, but which falls off much more slowly at large angles.

P. Pizzi [18] collected neutron scattering measurements of $\mathrm{Si}_{3} \mathrm{~N}_{4}$ materials at various densities and heat treatments to detect microvoids from multiple refraction effects. Two samples were reaction bonded with densities of 2.28 and $2.49 \mathrm{gm} / \mathrm{cm}^{3}$ and several were hot pressed with densities from 3.03 to 3.19 $\mathrm{g} / \mathrm{cm}^{3}$. Plots of intensity versus $\mathbf{Q}$ (or $K$ ) for the reaction bonded and hot pressed $\mathrm{Si}_{3} \mathrm{~N}_{4}$ at two wavelengths (fig. 11) reveal wavelength dependency suggesting the presence of multiple refraction neutron scattering. Results for three $\mathrm{Si}_{3} \mathrm{~N}_{4}$ samples with densities of $2.28,2.46$ and $3.18 \mathrm{gm} / \mathrm{cm}^{3}$ give radius values for the voids of 3,5 and $2.7 \mu \mathrm{m}$ respectively. This would indicate phase shifts, $\rho$ of 4.6 to 8.6 (see fig. 2) which probably fall within the intermediate

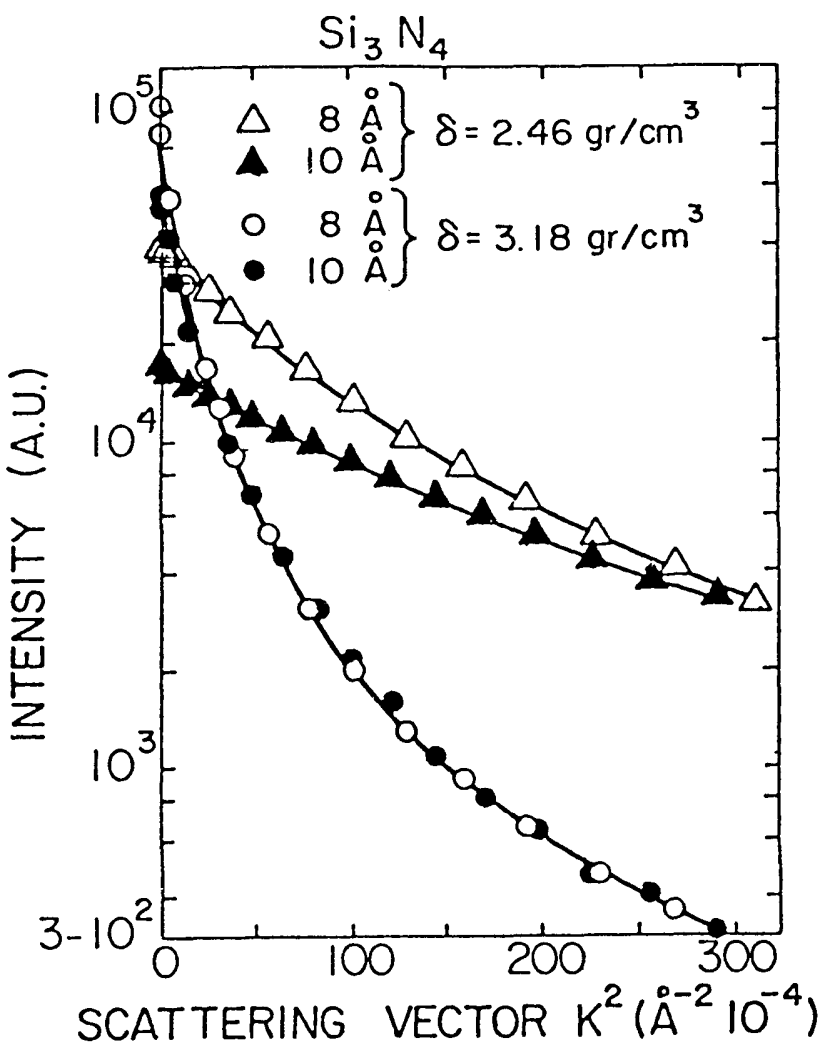

Figure 11-SANS from two samples of $\mathrm{Si}_{3} \mathrm{~N}_{4}$ measured at $\lambda=0.8$ and $1.0 \mathrm{~nm}$. The scattering vector $\mathbf{K}$ is the same as $\mathbf{Q}$ in this paper. Densities of the two samples were $2.46 \times 10^{3}$ and $3.18 \times 10^{3} \mathrm{~kg} / \mathrm{m}^{3}$, respectively (Ref. [18] is source). beam broadening region between the diffraction and multiple refraction limits.

\section{Beam Broadening Region}

Porosity is a critical aspect in the densification process of a sintered ceramic material. To elucidate the extent of such porosity, a quantitative study with SANS has been conducted at NBS to determine average pore size. Rather than restricting the SANS measurements to the typical 1 to $100 \mathrm{~nm}$ size regime of SANS diffraction, we have explored the neutron beam broadening region by extending the SANS characterization into the tens of micrometer size regime. This extension of SANS technique to larger sizes is an important result because it allows a greater overlap of SANS characterization with other NDE techniques.

Two samples of $\mathrm{YCrO}_{3}$ were fabricated from pure powders by isostatic pressing at $207 \mathrm{MPa}(30,000 \mathrm{psi})$; one sample was then sintered [19]. The density of the "green" compact (the unfired ceramic) was approximately $57 \%$ of theoretical density and that of the sintered material was approximately $94 \%$. The starting ceramic powder, with approximately $30 \%$ of theoretical density, was also examined. Since beam broadening measurements are wavelength dependent, SANS experiments were taken at six or seven wavelengths of the following: $0.485,0.545,0.625,0.70$, $0.80,0.90,0.95,1.0 \mathrm{~nm}$. The results reveal a striking difference between the samples as illustrated in figures 12 and 13 which are SANS spectra for the sintered and "green" compact specimens respectively. The sintered material (fig. 12) shows little wavelength dependence but the "green" compact reveals dramatic beam broadening which is strongly wavelength dependent (see fig. 13). This dependence is illustrated in figure 14 by plotting the normalized intensity versus scattering vector $\mathbf{Q}$ for five wavelengths.

The direct beam is wavelength independent with respect to the scattering angle, $\epsilon$ and is defined in part by the instrumental collimation. Beam broadening data can resemble a Gaussian distribution at low $\mathbf{Q}$ values where the full width at half maximum, $\Delta \epsilon$ can be determined by the Gaussian standard deviation parameter $\sigma_{G}$ as shown below:

$$
I=I_{\mathrm{o}} \exp \left(-\mathbf{Q}^{2} / 2 \sigma_{G}^{2}\right)
$$

For full width at half maximum $\Delta Q=2.355 \sigma_{G^{*}}$

Since $Q=2 \pi \epsilon / \lambda$, the $\Delta \epsilon=0.3748 \lambda \sigma_{G}$. 

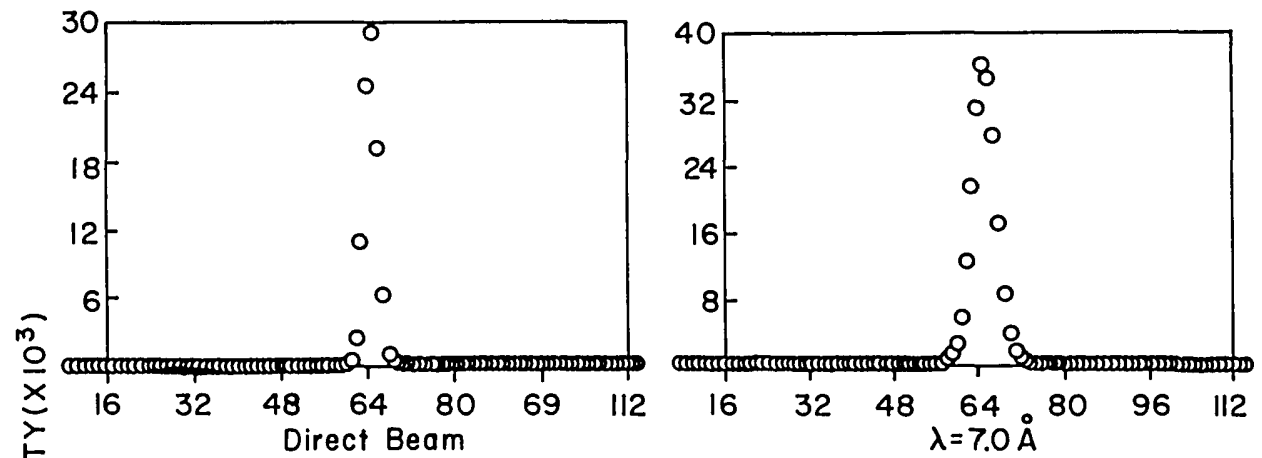

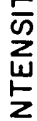
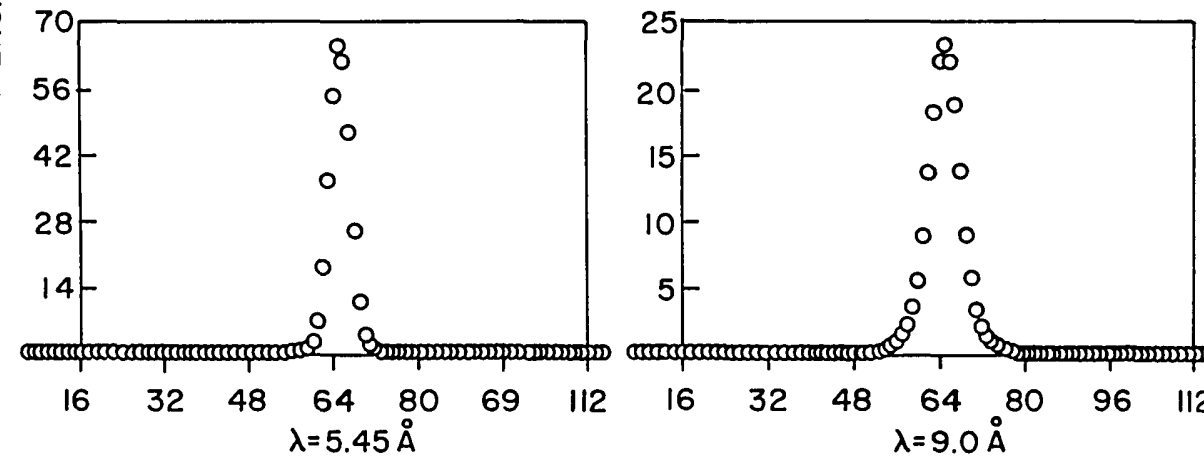

ROW
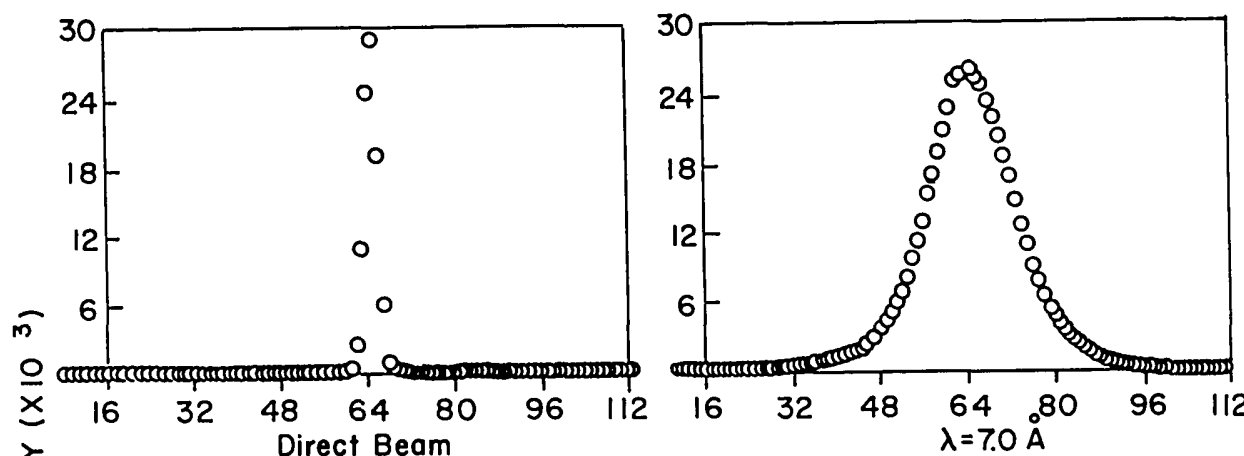

㐫
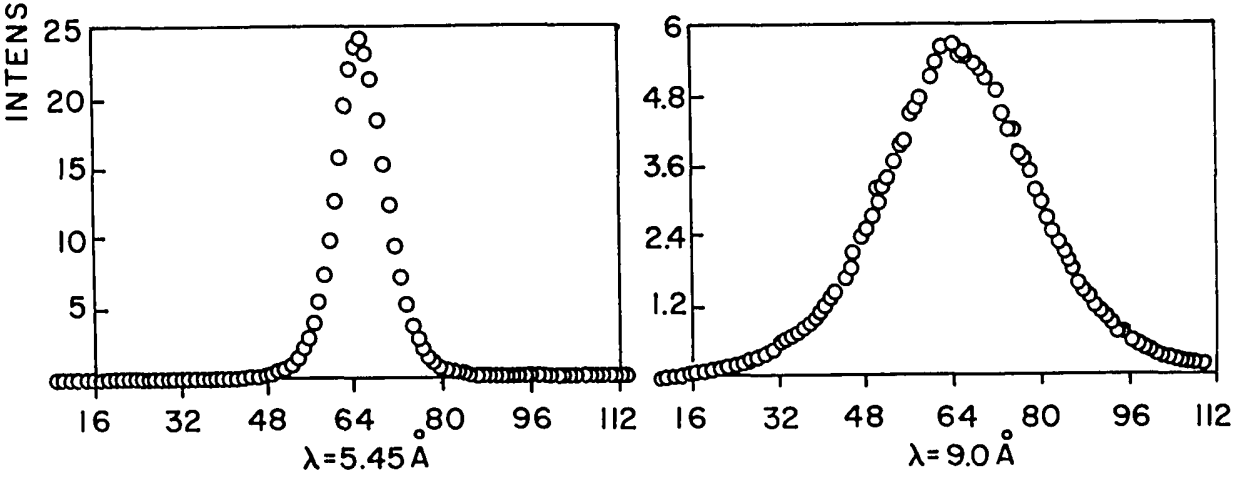

ROW
Figure 12-SANS spectra for a sintered compact of $\mathrm{YCrO}_{3}$ at three wavelengths: 0.545 , lower left, 0.7 , and $0.9 \mathrm{~nm}$. Plotted is the scattering intensity versus a a linear column slice through the center of the neutron scattering plane (as indicated by the row number).
Figure 13-SANS spectra for a "green" compact of $\mathrm{YCrO}_{3}$ at three wavelengths: $0.545,0.7$, and $0.9 \mathrm{~nm}$. Plotted is the scattering intensity versus a linear column slice through the center of the neutron scattering plane (as indicated by the row number). 
Figure 14-Normalized scattering intensity versus scattering vector, $\mathbf{Q}$, for neutron scattering from a "green" $\mathrm{YCrO}_{3}$ compact at five wavelengths.

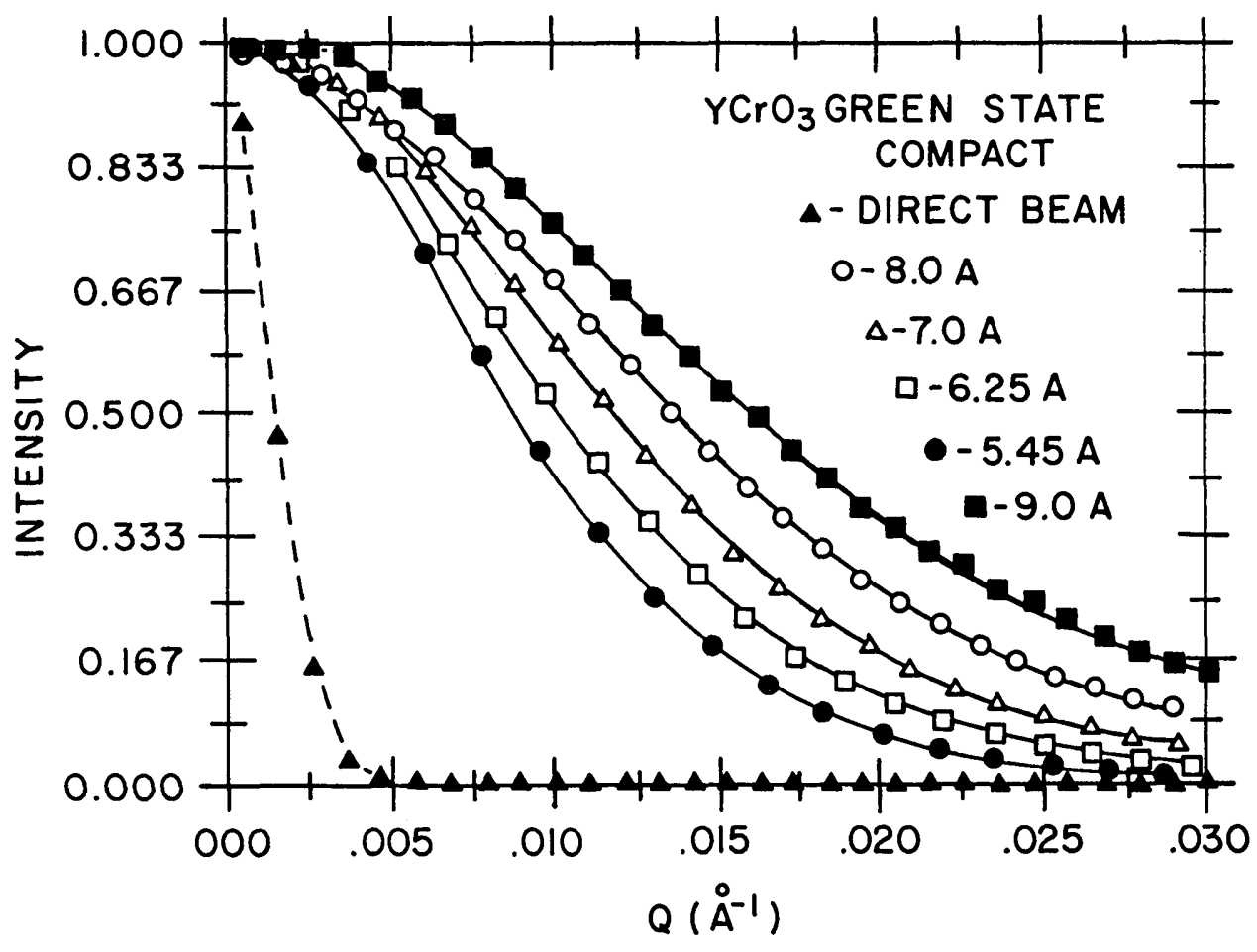

The full width at half maximum for the direct beam, $\epsilon_{b}$, was determined for two different collimating conditions. In the fine pin-hole geometric configuration $(12$ and $8 \mathrm{~mm})$ the $\epsilon_{b}$ is $4.62 \times 10^{-3} \pm 10^{-5}$ radians which was used in the $\mathrm{YCrO}_{3}$ materials. The beam broadening experiment of $\mathrm{Si}_{3} \mathrm{~N}_{4}$ shown in figure 6 was obtained under focussed collimation conditions and the $\epsilon_{b}$ is $3.882 \times 10^{-3} \mathrm{rad} . \pm 10^{-6}$. The $\Delta \epsilon$ value contains both the beam broadening scattering and that due strictly to the direct beam, thus the direct beam, $\epsilon_{b}$, must be subtracted from the experimentally determined value, $\epsilon$.

$$
\Delta \epsilon=\left[\epsilon^{2}-\epsilon_{b}^{2}\right]^{1 / 2}
$$

An example of the data (squares) and Gaussian fit (dashed line) for the "green" compact of $\mathrm{YCrO}_{3}$ at $\lambda=0.625 \mathrm{~nm}$ is shown in figure 15 .

Although the qualitative aspects of the data clearly demonstrate a strong effect of ceramic processing on the neutron scatterers population in these materials, quantitative measures of the particle or void size, shape and size distribution are less straightforward. Moreover the $\Delta b, \lambda$ and probably $R$ values correspond to phase shifts well within the intermediate range of values for which the neutron scattering is not expected to be analyzable by multiple refractive behavior alone. Therefore, a generalized beam

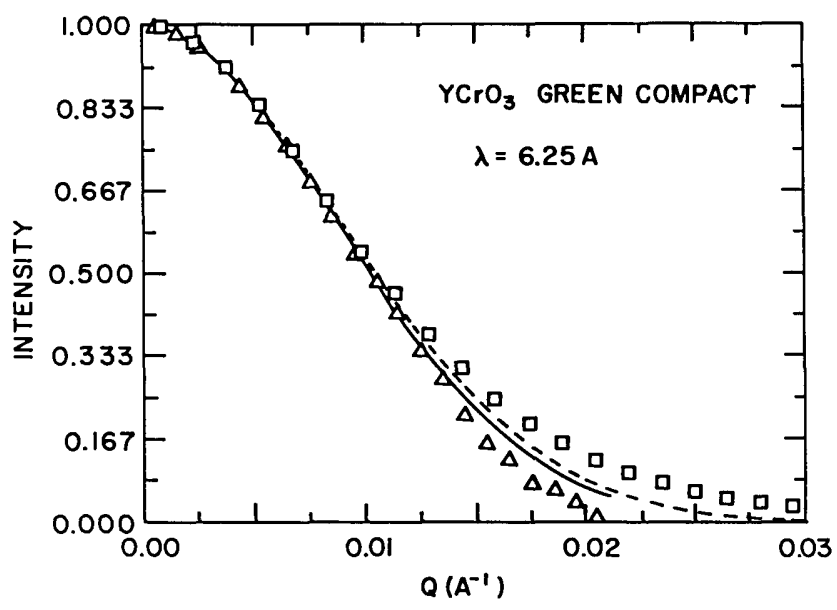

Figure 15-Normalized intensity versus $Q$ from a "green" $\mathrm{YCrO}_{3}$ compact at $\lambda=0.625 \mathrm{~nm}$. The squares are the data with the direct beam and the dashed line represents the Gaussian fit to the low $\mathbf{Q}$ region. The triangles are the theoretically derived beam broaden data points which do not include the direct beam. The solid line is the Gaussian fit through this data fit.

broadening theory [6] relevant for this region and multiple refraction has been developed to quantitatively analyze the SANS data for densified ceramics and other distributed defects in this size regime. Figure 15 contains a generated data set from the theory (triangles) and the Gaussian fit to these data points (solid line). The $\Delta \epsilon$ does not contain the direct beam 
portion. The radius, void (or particle) density ratio and shape factor can be obtained from this theory, which can be expanded to consider particle packing, polydispersivity and various shapes of particles and voids other than spheres. Excellent agreement of data and theoretical values for $\Delta \epsilon$ can be seen in figure 16 and table 3 . The average radius void size in the $\mathrm{YCrO}_{3}$ "green" compact material is $0.17 \mu \mathrm{m}$ and has a void density ratio of 0.42 compared to the overall density ratio of 0.43 .

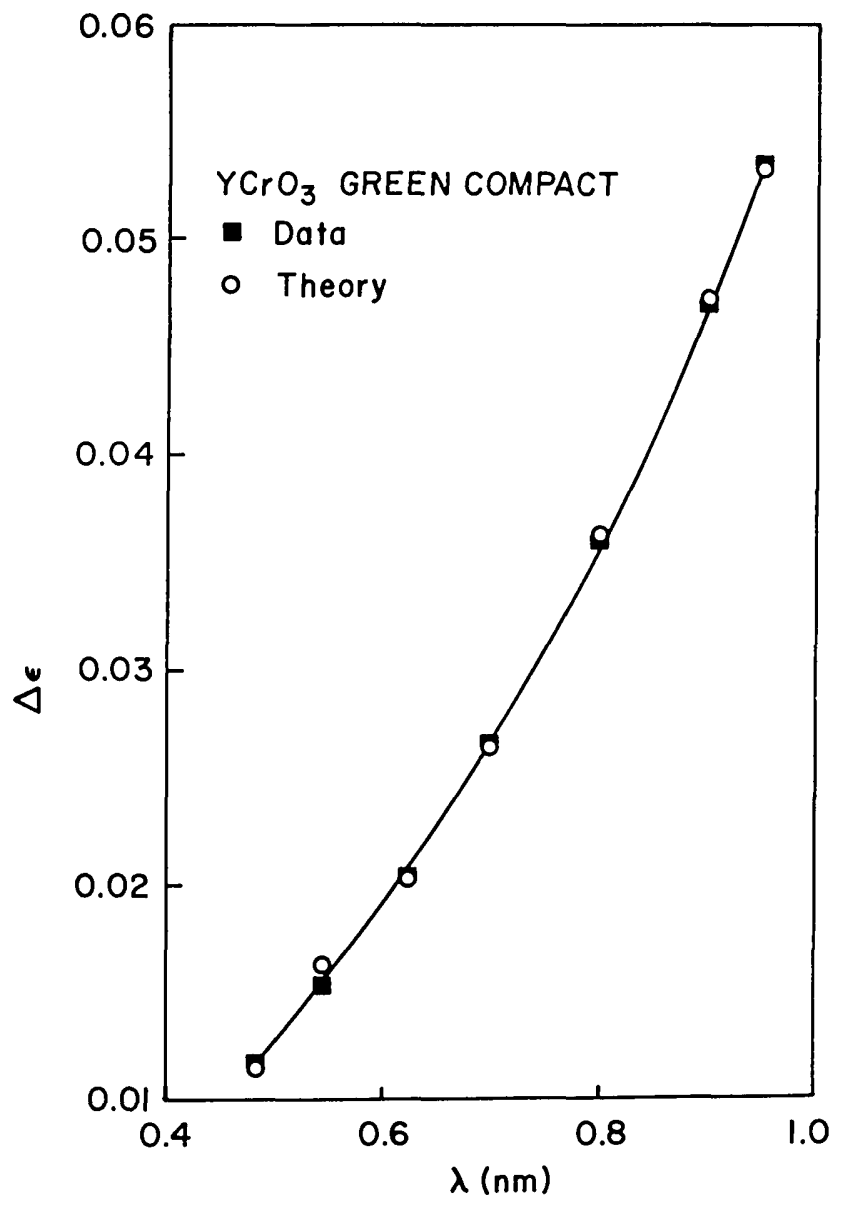

Figure 16-Full width at half maximum, $\Delta \epsilon$ (in radians) versus the wavelength, $\lambda$, for voids in the "green" compact of $\mathrm{YCr}_{3}$. The squares are the data and the circles are the $\Delta \epsilon$ values derived from theory.

A powder sample of $\mathrm{YCrO}_{3}$ was examined to compare previously determined average particle size values with that obtained from SANS experiments. The $\mathrm{YCrO}_{3}$ powder particles were ultrasonically dispersed and magnetically stirred at a temperature of $32^{\circ} \mathrm{C}$ [20]. A plot of the cumulative mass percent versus the equivalent spherical diameter in $\mu \mathrm{m}$, determined by sedimentation methods, is shown in
Table 3. $\Delta \epsilon$ values for $\mathrm{YCr}_{3}$ " "green" compact where $\Delta b=$ $5.277 \times 10^{-4} \mathrm{~nm}^{-2}$, void density ratio $=0.42, T=12.2 \mathrm{~mm}, R=0.17$ $\mu \mathrm{m}$

\begin{tabular}{lcc}
\hline \hline$\lambda(\mathrm{nm})$ & Data & $\Delta \epsilon$ (radians) \\
\hline 0.485 & 0.01156 & Theory \\
0.545 & 0.01525 & 0.01137 \\
0.625 & 0.02038 & 0.01611 \\
0.7 & 0.02660 & 0.02028 \\
0.8 & 0.03598 & 0.02645 \\
0.9 & 0.04700 & 0.03617 \\
0.95 & 0.05338 & 0.04711 \\
& & 0.05322 \\
\hline
\end{tabular}

figure 17. The two runs were reproducible with an apparent small distribution of powder sizes present. The average diameter value is approximately $1.4 \mu \mathrm{m}$ (or $R=0.7 \mu \mathrm{m}$ ) and agrees well with the $R$ value obtained from the SANS analysis of $0.74 \mu \mathrm{m}$. The data (squares) and theory values (circles) for $R=0.74$ $\mu \mathrm{m}$ are shown in figure 18. If we assume that multiple refraction effects only are present, then a fairly good fit to the data using von Nardroff formula for random spheres can be obtained (triangles and dashed line in fig. 18). However the number of scattering events determined from this fit is 33.4 which requires $R$ to be $62 \mu \mathrm{m}$. This is clearly outside the range of possible radius values for this material.

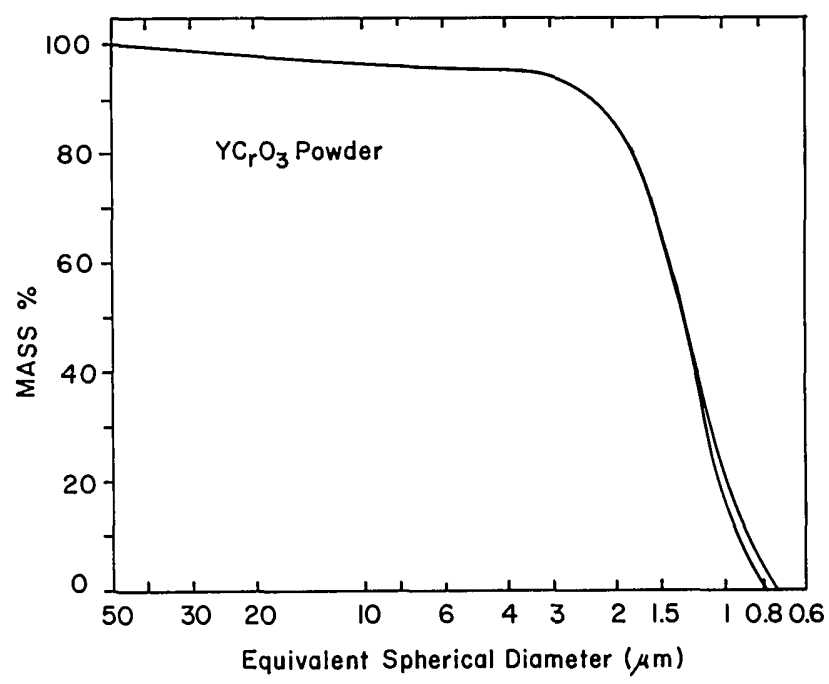

Figure 17-Size distribution of $\mathrm{YCrO}_{3}$ powder particles. A plot of cumulative mass percent versus the equivalent spherical diameter by ultrasonic dispersion technique.

The general beam broadening theory and SANS technique allows us to study the densification process in a nondestructive way. It is being extended to study the sintering of spinels $\left(\mathrm{MgAl}_{2} \mathrm{O}_{4}\right)$ as a function of 


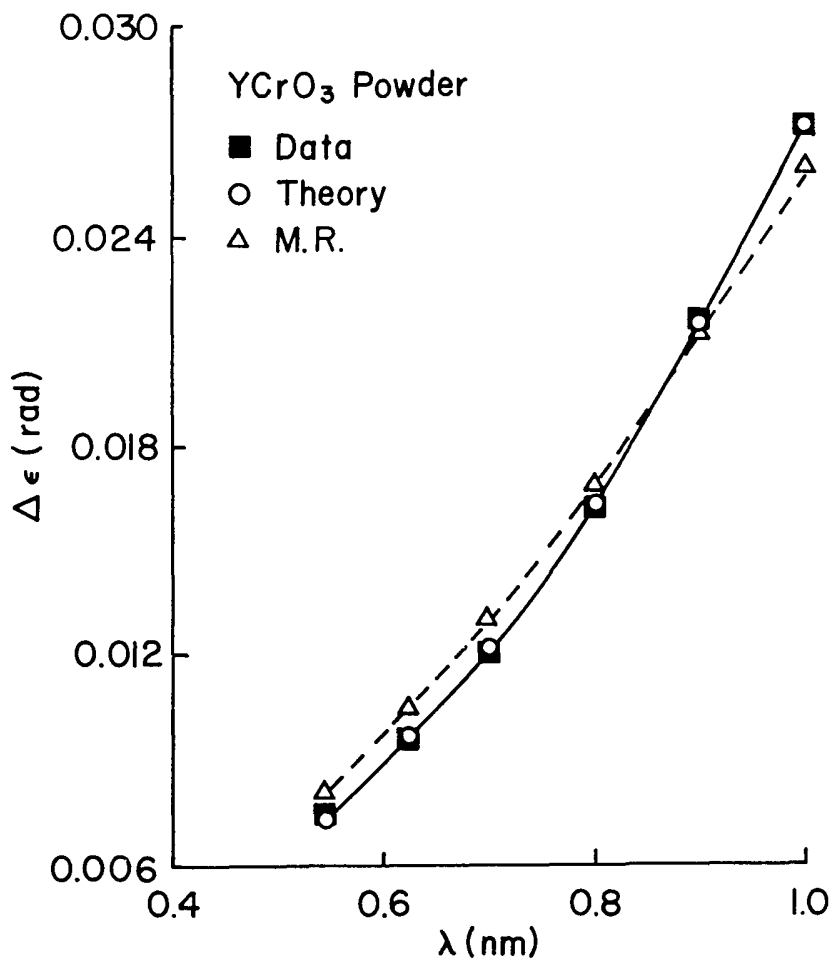

Figure 18-Full width at half maximum, $\Delta \epsilon$ (in radians) versus $\lambda$ for $\mathrm{YCrO}_{3}$ powder particles. The data (squares) theoretically derived values (circles) and multiple refraction results (triangles) are given. temperature. Although the spinel powders have been heated at $1300^{\circ} \mathrm{C}$ for 12 hours, very little sintering has occurred (fig. 19) but sintering effects are apparent after only 3 hours at $1500^{\circ} \mathrm{C}$. Nevertheless the material is not fully sintered in that the $\epsilon_{b}$ of the direct beam (the blank) is significantly smaller than the $\epsilon$ of the spinel at $1500{ }^{\circ} \mathrm{C}$. In situ as well as other ceramic processing experiments are expected to fully develop the capabilities of this new approach in SANS. It should be of interest to other material disciplines such as magnetic broadening effects, pores in metal alloys and colloidal chemistry.

\section{References}

[1] Kostorz, G. Treatise on Materials Science and Technology, Vol. 15, ed., G. Kostorz, Academic Press, New York: 5-8; 1979.

[2] Glinka, C. J. AIP Conference Proceedings No. 89, J. Faber, ed., Neutron Scattering-1981, p. 395.

[3] Weertman, J. R. Nondestructive Evaluations: Microstructural Characterization and Reliability Strategies, eds., O. Buck and S. M. Wolf, American Institute of Mining, Metallurgical, and Petroleum Engineers, New York: 147-168; 1981.

[4] Kostorz, G. Treatise on Materials Science and Technology, Vol. 15, ed., G. Kostorz, Academic Press, New York: 227-289; 1979.

[5] Herman, H. Non-Destructive Evaluation of Materials with Cold Neutron Beams, report to Naval Air Systems Command, Contract No. N00019-77-M-0418, Washington, DC: Dec. 1977.

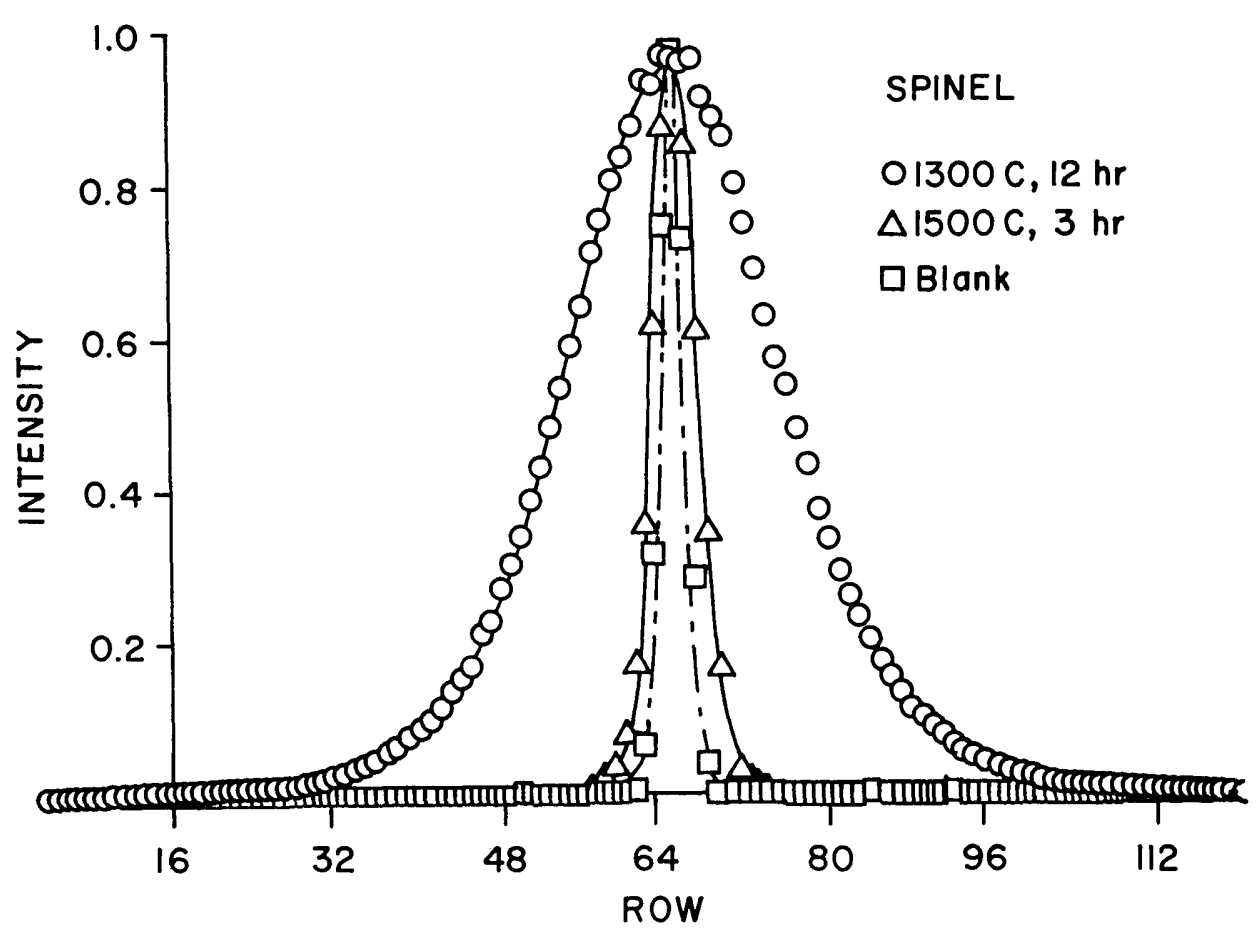

Figure 19-SANS spectra for a spinel $\left(\mathrm{MgAl}_{2} \mathrm{O}_{4}\right)$ at $\lambda=0.9 \mathrm{~nm}$. The circles represent the SANS spectra of the spinel with 12 hours of heat treatment at $1300^{\circ} \mathrm{C}$. After 3 hours of $1500^{\circ} \mathrm{C}$ temperature (triangles) the spinel is partially sintered but slight neutron beam broadening can be seen from that of the direct beam (squares). 
[6] Berk N. F.; Hardman-Rhyne, K., to be published.

[7] Weiss, R. J. Phys. Rev. 83: 379; 1951.

[8] Snyder, H. S.; Scott, W. T. Phys. Rev. 76: 220; 1949.

[9] Wright, A. F. Neutron Scattering 1981 AIP Conference Proceedings, ed., J. Faber: 359; 1982.

[10] Page, R. A.; Lankford, J. Communications of the American Ceramic Society: C-146; 1983.

[11] Wright, A. F.; Nunn, S.; Brett, N. H., to be published in the proceedings of the conference on zirconia in Stuttgart: 1983.

[12] Case, E. D.; Glinka, C. J., to be published in the J. of Matl. Sci.

[13] Hardman-Rhyne, K.; Berk, N. F.; Tighe, N., to be published.

[14] Porod, G. Acta Phys. Austriaca 2: 255; 1948.

[15] Guinier, A. X-ray diffraction, Chapter 10, W. H. Freeman and Company, San Francisco: 1963.

[16] Debye, P.; Anderson, H. R.; Brumberger, H. J. Appl. Phys. 28: $679 ; 1957$

[17] von Nardroff, R. Phys. Rev. 28: 240; 1926.

[18] Pizzi, P. Symposium on Fracture Mechanics of Ceramics, Vol. 3, eds., R. C. Bradt, D. P. H. Hasselman and F. F. Lange, Penn. State; Plenum Press, New York: 85; 1978.

[19] Negas, T.; Domingues, L. P., private communication: 1983.

[20] Robbins, C., private communications: 1983. 